\title{
Control of Staphylococcus aureus Quorum Sensing by a Membrane-Embedded Peptidase
}

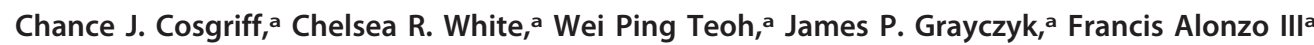 \\ aDepartment of Microbiology and Immunology, Loyola University Chicago Stritch School of Medicine, Maywood, Illinois, USA
}

ABSTRACT Gram-positive bacteria process and release small peptides, or pheromones, that act as signals for the induction of adaptive traits, including those involved in pathogenesis. One class of small signaling pheromones is the cyclic autoinducing peptides (AIPs), which regulate expression of genes that orchestrate virulence and persistence in a range of microbes, including staphylococci, listeriae, clostridia, and enterococci. In a genetic screen for Staphylococcus aureus secreted virulence factors, we identified an $S$. aureus mutant containing an insertion in the gene SAUSA300_1984 (mroQ), which encodes a putative membrane-embedded metalloprotease. A $\triangle m r o Q$ mutant exhibited impaired induction of Toll-like receptor 2-dependent inflammatory responses from macrophages but elicited greater production of the inflammatory cytokine interleukin- $1 \beta$ and was attenuated in a murine skin and soft tissue infection model. The $\Delta m r o Q$ mutant phenocopies an $S$. aureus mutant containing a deletion of the accessory gene regulatory system (Agr), wherein both strains have significantly reduced production of secreted toxins and virulence factors but increased surface protein A abundance. The Agr system controls virulence factor gene expression in $S$. aureus by sensing the accumulation of AIP via the histidine kinase AgrC and the response regulator AgrA. We provide evidence to suggest that MroQ acts within the Agr pathway to facilitate the optimal processing or export of AIP for signal amplification through AgrC/A and induction of virulence factor gene expression. Mutation of MroQ active-site residues significantly reduces AIP signaling and attenuates virulence. Altogether, this work identifies a new component of the Agr quorum-sensing circuit that is critical for the production of S. aureus virulence factors.

KEYWORDS Agr, Staphylococcus aureus, accessory gene regulator, peptidase, peptide signaling, quorum sensing, virulence

uorum sensing in Gram-positive bacteria occurs via the maturation and release of small signaling oligopeptides (1). These peptides can be linear but may also undergo cyclic ring formation, as is known to occur with the Staphylococcus aureus autoinducing peptide (AIP) $(2,3)$. In either scenario, a precursor peptide is synthesized and processed prior to or after export from the bacterial cell. While many signaling molecules of Gram-negative bacteria are freely diffusible, the peptides of Gram-positive bacteria generally must transit the membrane via a dedicated transporter $(4,5)$. After processing and transport, the peptide either is imported back into the bacterial cell or transmits a signal from the extracellular environment by binding to membraneembedded sensor histidine kinases (6). Peptide signaling culminates in a change in gene expression mediated by transcription factors that respond to the peptide. Many Gram-positive bacterial pathogens use these quorum-sensing peptides to induce gene expression programs that promote virulence adaptations, such as competence, toxin production, biofilm formation, and the establishment of persistence traits. Because of its importance in activating virulence programs in S. aureus, quorum-sensing inhibition has been the focus of many therapeutic initiatives (7-14).
Citation Cosgriff CJ, White CR, Teoh WP, Grayczyk JP, Alonzo F, III. 2019. Control of Staphylococcus aureus quorum sensing by a membrane-embedded peptidase. Infect Immun 87:e00019-19. https://doi.org/10.1128/ IAl.00019-19.

Editor Nancy E. Freitag, University of Illinois at Chicago

Copyright $\odot 2019$ American Society for Microbiology. All Rights Reserved.

Address correspondence to Francis Alonzo III, falonzo@luc.edu.

C.J.C. and C.R.W. contributed equally to this article.

For a companion article on this topic, see https://doi.org/10.1128//Al.00002-19.

Received 9 January 2019

Returned for modification 14 February 2019

Accepted 23 February 2019

Accepted manuscript posted online 4

March 2019

Published 23 April 2019 
The ability of S. aureus to infect host tissues and cause acute and chronic disease is partially due to its use of complex gene regulatory systems that control virulence factor gene expression (15-17). S. aureus employs 16 two-component systems that contribute to virulence and a range of environmental adaptations (18-25). One of the central two-component systems in $S$. aureus that regulates virulence factor production is the accessory gene regulatory $(\mathrm{Agr})$ system $(15,26)$. The components of the Agr system are encoded in an operon containing 4 open reading frames (agrBDCA) (3). These open reading frames encode the histidine kinase $\mathrm{AgrC}$ and its cognate response regulator, AgrA, as well as AgrB, a protease that cleaves AgrD, the precursor peptide of AIP. The AgrD precursor peptide is $\sim 46$ amino acids in length with a central stretch of 7 to 9 amino acids that comprise mature AIP. The C-terminal charged tail of AgrD is cleaved by AgrB (27-30), which subsequently mediates peptide cyclization by inducing formation of a thiolactone linkage between the C-terminal carbonyl and the sulfur atom of a conserved cysteine side chain (29). The N-terminal 18 residues form an amphipathic $\alpha$-helix that anchors the peptide to the cell membrane by lateral association and that is required for processing and transport (31). The remaining processing and transport mechanisms for AIP are not fully defined, but in some $S$. aureus strains, the type I signal peptidase SpsB is involved in peptide cleavage (32). Clinical isolates of S. aureus can be stratified into one of four Agr groups (I, II, III, and IV) that harbor allelic variants of AgrD, AgrB, and AgrC (3, 30, 33-35). Recognition of AIP from different Agr types is group specific, and AIP variants (except AIP I and IV) inhibit the activity of noncognate AgrCs (36-40). S. aureus strains of all Agr types are known to cause clinical disease; therefore, an understanding of the divergence between Agr types is paramount to our understanding of pathogenesis and population dynamics $(33,41,42)$. The final outcome of Agr activation in S. aureus is the production of toxins and other virulence factors that promote disease (3). Coincident with its critical role in regulating the production of virulence factors, strains of $S$. aureus with defects in Agr function are attenuated in skin and lung infection models, underscoring the significance of this regulatory system to pathogenesis (43-46).

We recently published the results of a screen for $S$. aureus virulence factors using a transposon mutant library of the methicillin-resistant S. aureus (MRSA) strain JE2 (47). We hypothesized that identification of $S$. aureus mutants with secreted factors that positively or negatively modulate macrophage activation would yield good virulence factor candidates, given the significant immunopathology associated with $S$. aureus infection and the major involvement of $S$. aureus-macrophage interactions in disease. Indeed, the screen successfully uncovered a range of previously unstudied mediators of virulence that our laboratory has been investigating in recent years (47-49). This study relates to an insertion mutant identified in the above-mentioned screen whose supernatant elicited the production of high levels of interleukin-1 $\beta$ (IL-1 $\beta$ ) but reduced the secretion of other proinflammatory cytokines, including keratinocyte-derived chemokine (KC) and IL-6, by macrophages (47). The transposon insertion disrupted a single open reading frame, SAUSA300_1984, which encodes a putative type II CAAX metalloprotease.

Type II CAAX proteases are multipass transmembrane proteins with two conserved catalytic motifs, EEXXXR and FXXXH (50). The diglutamate in the EEXXXR motif facilitates the activation of water for nucleophilic attack, whereas the histidine in the FXXXH motif is important for metal binding. Both motifs are thought to be necessary for enzyme activity. In eukaryotes, type II CAAX proteases are involved in prenylation pathways that target proteins to the cell membrane through lipidation of a conserved cysteine within a CAAX motif (50). In bacteria, the function of CAAX proteases is more ambiguous, although their activities have been linked to immunity to bacteriocins in some species (51-54). In S. aureus, there are at least four putative type II CAAX metalloproteases that are also annotated as members of the abortive infectivity (Abi) protein family. The Abi nomenclature for this class of metalloproteases was originally assigned based upon studies of phage resistance mechanisms in Lactococcus lactis (55). Despite the frequent use of this terminology, members of the Abi protein family are not 
believed to exert functions related to phage resistance (50). Three of the four type II CAAX proteases in S. aureus have roles in surface protein display (SpdA, SpdB, and SpdC [also known as LyrA]) $(56,57)$. SpdC was recently found to play a role in activation of the WalKR two-component system in S. aureus (58). SpdC directly interacts with the histidine kinase WalK at the division septum, where it appears to have a negative effect on WalK kinase activity. SpdC interacts with WalK through its membrane-spanning domain, and due to sequence divergence from other type II CAAX proteases in $S$. aureus, its function likely does not require proteolytic activity (56-58). Additional bacterial two-hybrid studies suggest that SpdC interacts with $S$. aureus histidine kinases SaeS, SrrB, VraS, GraS, and ArlS but not the histidine kinase of the Agr system, AgrC. Whereas SpdA, SpdB, and SpdC orchestrate cell wall homeostasis in a manner that is independent of catalytic activity, the fourth type II CAAX protease, SAUSA300_1984, appears to be functionally distinct and does not modulate cell wall integrity in any known way (56). To date, no additional functions for SAUSA300_1984 have been described. Though it has not yet been investigated in great detail, at least one other study has implicated a type II CAAX protease in the regulation of virulence gene expression. The CAAX protease of group B Streptococcus, Abx1, acts as a regulator of the CovSR two-component system through its histidine kinase CovS, where overexpression of Abx1 promotes activation of CovS (59). Thus, there is mounting evidence for a conserved function of type II CAAX proteases in the regulation of two-component system signaling in bacteria, which in these two instances appears to operate through interaction with a histidine kinase and is independent of catalytic activity.

In this work, we report the identification of SAUSA300_1984, named membrane protease regulator of Agr quorum sensing (MroQ). We determined that MroQ promotes Toll-like receptor 2 (TLR2)-mediated activation of innate immune cells while preventing induction of IL- $1 \beta$ by primary murine macrophages in vitro. This altered inflammatory profile is recapitulated in in vivo infection models, where MroQ promotes inflammatory pathology, cytokine secretion, and bacterial persistence in a model of skin and soft tissue infection. Further investigation into the mode of action of MroQ determined that it acts to regulate the activity of the Agr quorum-sensing system, as evidenced by reduced secreted virulence factors and increased surface protein expression in a $\Delta m r o Q$ mutant. Our data suggest that MroQ may interface with the Agr system at the level of peptide processing or transport to blunt activation of the AgrC/A two-component system, which remains otherwise responsive in a $\triangle m r o Q$ mutant background. Altogether, our data support a model whereby MroQ controls gene expression at the level of the Agr system, with significant impacts on the virulence potential of S. aureus.

\section{RESULTS}

MroQ is a predicted type II CAAX protease that blunts TLR2-mediated recognition of S. aureus by macrophages. The $m r o Q$ open reading frame is located within the core genome of $S$. aureus and is positioned four open reading frames upstream of the Agr system (Fig. 1A). The gene is flanked by sdrH and groEL groES, which encode the serine aspartate repeat family protein $\mathrm{SdrH}(60)$ and the GroEL/ES stress response chaperone system (61), respectively (Fig. 1A). Phyre2 prediction software analysis of the MroQ amino acid sequence suggests a topology containing seven transmembrane helices with the $\mathrm{N}$ terminus positioned in the cytosol and the $\mathrm{C}$ terminus positioned in the extracellular space, though the weaker predictive strength of the topology analysis at the $\mathrm{N}$ and $\mathrm{C}$ termini may suggest alternative arrangements in the membrane (Fig. 1B). Consistent with its annotation as a type II CAAX protease, MroQ contains a conserved diglutamate motif, EEXXXR (E141-E142), and the FXXXH (H180) metal coordination motif that shares sequence identity with previously characterized CAAX proteases SpdA and SpdB, with weaker conservation than SpdC (Fig. 1C). We previously determined that supernatant derived from a SAUSA300_1984 transposon insertion mutant compromises macrophage activation (47). To begin interrogating the function of MroQ in greater detail, we first generated an in-frame deletion mutant and complementation strain that expresses $m r o Q$ from an ectopic site in the S. aureus chromosome 


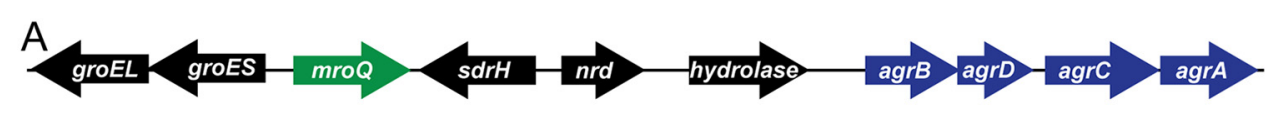

B PHYRE2 Topology Prediction
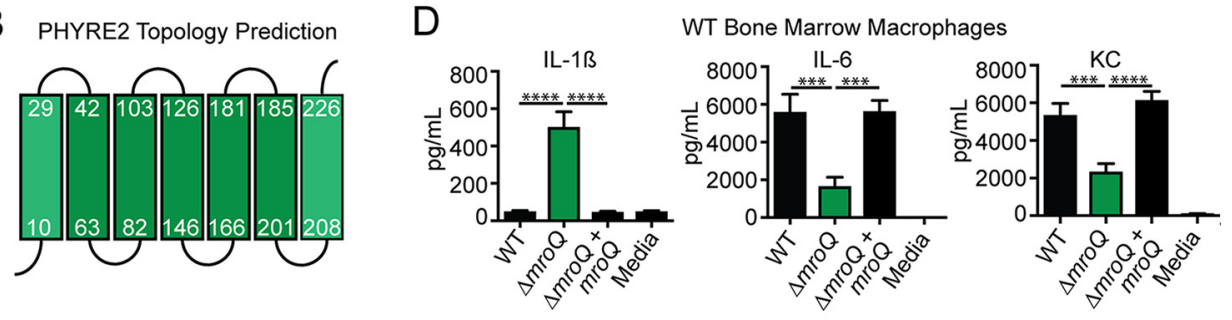

C

MYOQ LEEYVFRK---IFALAHN

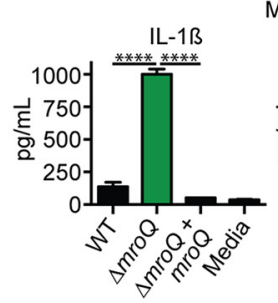

MyD88-\% Bone Marrow Macrophages

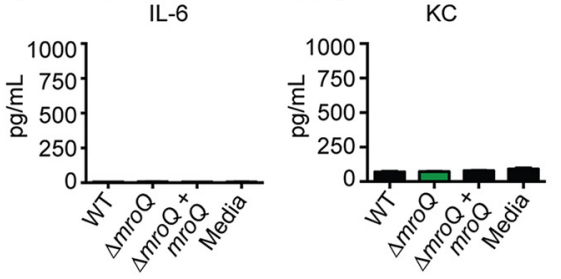

FIG 1 MroQ is a putative membrane-embedded protease that affects macrophage activation by S. aureus secreted factors. (A) Illustration of the gene arrangement surrounding $m r o Q$ and its proximity to the agr operon. nrd, nitroreductase family protein; $s d r H$, serine aspartate repeat family protein; hydrolase, carbon-nitrogen family hydrolase. (B) Phyre2 topology prediction analysis of MroQ within the membrane. Green boxes, predicted $\alpha$-helices. (C) Amino acid sequence alignment of the EEXXXR and FXXXH motifs that comprise the type II CAAX protease active site among four predicted family members in $S$. aureus. (D) IL-1 $\beta$, IL-6, and KC production by BMM after addition of supernatant from the WT, $\triangle m r o Q$, or $\triangle m r o Q+m r o Q$ strain grown in TSB. (Top) WT BMM; (bottom) MyD88 ${ }^{-1-}$ BMM. The data shown are from one of at least three experiments conducted in triplicate. Means \pm SD are shown $(n=3)$. $P$ values were determined by one-way ANOVA with Tukey's posttest. ${ }^{* * *}, P<0.001$; ${ }^{* * * *}$, $P<0.0001$.

driven by its predicted native promoter (62). The wild-type (WT) strain, the $\triangle m r o Q$ mutant, and the $\triangle m r o Q$ mutant complement with mroQ (the $\triangle m r o Q+m r o Q$ strain) replicated identically in tryptic soy broth (TSB) and RPMI medium (see Fig. S1A and B in the supplemental material). We found that, similar to the findings for supernatant derived from the transposon insertion mutant, supernatant derived from a $\triangle m r o Q$ mutant enhanced the production of IL-1 $\beta$ by murine bone marrow-derived macrophages (BMM) but reduced the production of the inflammatory cytokine IL- 6 and the neutrophil chemotactic factor KC (Fig. 1D). The perturbations in IL- 6 and KC production were dependent on Toll-like receptor (TLR)-mediated recognition of $S$. aureus, as evidenced by the elimination of IL-6 and KC production in MyD88 ${ }^{-/-}$and $\mathrm{TLR2}^{-/-}$ macrophages but not TLR4 ${ }^{-\prime-}$ macrophages (Fig. 1D and S2A and B). In contrast, the enhanced IL-1 $\beta$ production did not depend on TLRs (Fig. 1D and S2A and B). These data indicate MroQ bears similarities to type II CAAX proteases, is positioned in close proximity to the agr locus in the $S$. aureus chromosome, and perturbs the activation of innate immune cells in culture through both TLR-dependent and -independent mechanisms.

MroQ is required for S. aureus virulence. Given the dramatic effect of the $\triangle m r o Q$ mutant on macrophage activation and the predicted effects that this might have on the inflammatory milieu during infection, we reasoned that the mutant would be compromised for virulence. To test this possibility, we infected mice intradermally with the WT, $\triangle m r o Q$, and $\triangle m r o Q+m r o Q$ strains. There were no differences in the number of bacterial CFU between strains at $72 \mathrm{~h}$ postinfection (Fig. S3A). However, significant dermonecrosis was evident in mice infected with the WT and $\triangle m r o Q+m r o Q$ strains but not those infected with the $\triangle m r o Q$ mutant (Fig. S3B). Consistent with reduced inflammatory tissue damage, mice infected with a $\triangle m r o Q$ mutant showed significantly reduced levels of the inflammatory chemokine monocyte chemotactic protein 1 (MCP-1) and trends toward reduced levels of IL-6, KC, CCL3, and CCL4 at $72 \mathrm{~h}$ (Fig. S3C). 


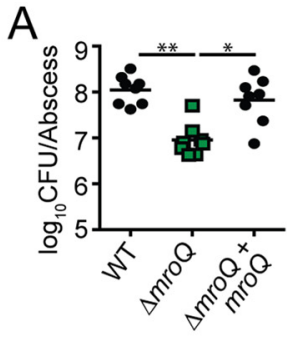

B

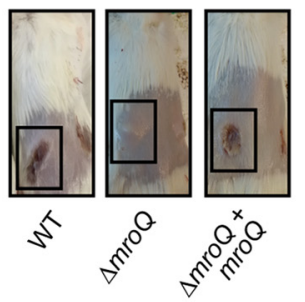

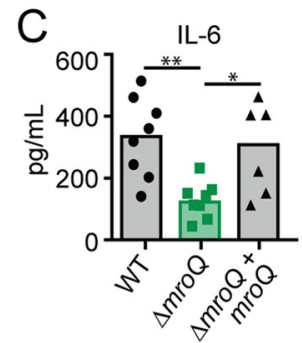
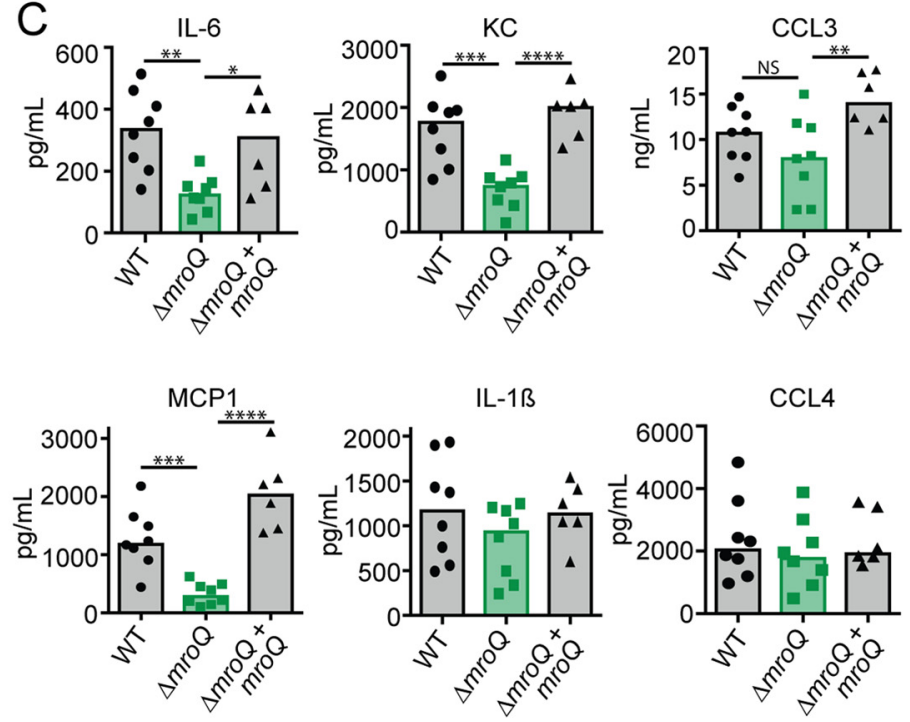

FIG 2 MroQ is important for S. aureus skin and soft tissue infection. (A) Bacterial burden in skin abscesses of mice at $120 \mathrm{~h}$ postinfection with the WT $(n=8), \Delta$ mroQ mutant $(n=8)$, or $\Delta m r o Q+$ mroQ mutant $(n=8)$. $P$ values were determined by a nonparametric one-way ANOVA (Kruskal-Wallis test) with Dunn's posttest. ${ }^{*}, P<0.05 ;{ }^{* *}, P<0.01$. (B) Representative images of skin abscesses at $120 \mathrm{~h}$ postinfection with the WT, $\triangle m r o Q$, and $\triangle m r o Q+m r o Q$ strains. (C) IL-6, KC, MCP-1, IL-1 $\beta$, CCL3, and CCL4 levels in abscess homogenates of mice infected with the WT ( $n=8)$, $\triangle m r o Q$ mutant $(n=8)$, or $\triangle m r o Q+m r o Q$ mutant $(n=6)$. $P$ values were determined by a nonparametric one-way ANOVA (Kruskal-Wallis test) with Dunn's posttest. ${ }^{*}, P<0.05 ;{ }^{* *}, P<0.01 ;{ }^{* * *}, P<0.001 ;{ }^{* * * *}, P<0.0001$; NS, not significant.

At $120 \mathrm{~h}$ postinfection, 10-fold fewer CFU were recovered from the abscesses of mice infected with a $\triangle m r o Q$ mutant (Fig. 2A). Gross pathological signs of disease, including large, ruptured, dermonecrotic abscesses, were not observed in $\Delta m r o Q$ mutantinfected mice, and the abscesses remained closed with little evidence of inflammation (Fig. 2B). There were significant reductions in IL-6, KC, MCP-1, and CCL3 at the abscess site, consistent with the findings of in vitro studies using BMM (Fig. 1D and 2C). IL-1 $\beta$ levels were equally elevated under all infection conditions compared to those at $72 \mathrm{~h}$ (Fig. 2C and S3C). These data indicate that MroQ is important for S. aureus skin and soft tissue infection.

A $\Delta$ mroQ mutant phenocopies a $\Delta$ agr mutant. $m r o Q$ was identified in a screen that used secreted factors to probe innate immune cell activation (47). Therefore, we sought to test if a $\triangle m r o Q$ mutant had notable differences in its secretome that might explain the BMM activation defects and reduced virulence. Exoprotein profile analysis indicated that the levels of secreted proteins were reduced in $\triangle m r o Q$ mutant supernatants (Fig. 3A). This defect in protein secretion closely resembled the profiles of an $S$. aureus strain with a deletion of the agr locus, the $\Delta$ agr mutant (Fig. $3 \mathrm{~A}$ ). Exoprotein analysis of a $\triangle m r o Q \Delta a g r$ double mutant revealed profiles identical to those of the $\triangle m r o Q$ and $\triangle a g r$ mutants (Fig. $3 \mathrm{~A}$ ). Furthermore, $\Delta m r o Q, \Delta a g r$, and $\Delta m r o Q \Delta a g r$ mutant supernatants induced BMM production of IL- $1 \beta$ but led to reduced levels of IL- 6 and KC with the same observed dependency on TLR2 (Fig. 3B and S4A to C). Incidentally, both $m r o Q$ and $a g r B$ transposon insertion mutants were identified to be inducers of IL- $1 \beta$ secretion in our prior transposon mutant library screen (47).

Given the similarities between the $\triangle m r o Q$ and $\triangle a g r$ mutants for defects in protein secretion and secreted factor-mediated perturbations in macrophage activation, we sought to determine whether or not a $\triangle m r o Q$ mutant exhibits other common phenotypes associated with a $\Delta a g r$ mutant. The Agr system regulates toxin secretion and surface protein production (3). Therefore, we compared the levels of lytic toxins and the Agr-regulated surface protein, protein A, between the $\triangle m r o Q$ and $\triangle a g r$ mutants $(3,63)$. We found that the toxins leukocidin $A B$ (LukA), Panton-Valentine (PV) leukocidin (LukS-PV), and alpha-hemolysin (Hla) were reduced in abundance in a 


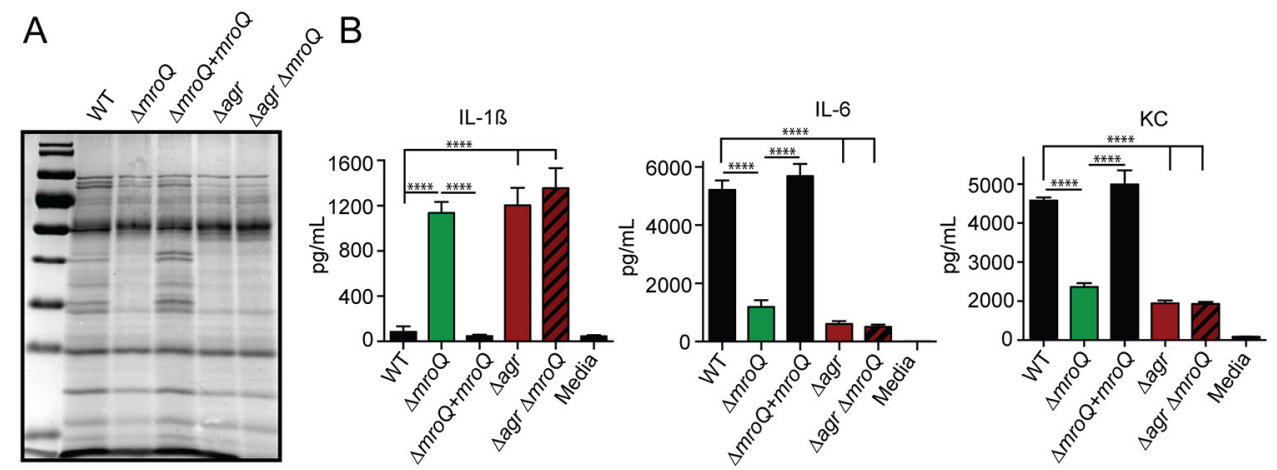

FIG 3 A $\triangle m r o Q$ mutant resembles a $\triangle a g r$ mutant for protein secretion and perturbations in macrophage activation. (A) TCA-precipitated exoproteins from the WT, $\triangle m r o Q, \triangle m r o Q+m r o Q, \triangle a g r$, and $\triangle a g r \Delta m r o Q$ strains collected after growth in TSB. (B) IL-1 $\beta$, IL-6, and KC production by BMM after addition of supernatant from the WT, $\triangle m r o Q$, $\triangle m r o Q+m r o Q, \Delta a g r$, and $\triangle a g r \Delta m r o Q$ strains grown in TSB. The data shown are from one of at least three experiments conducted in triplicate. Means \pm SD are shown $(n=3) .{ }^{* * * *}, P<0.0001$ by one-way ANOVA with Tukey's posttest.

$\triangle m r o Q$ and $\Delta a g r$ mutant, while surface protein A levels were increased (Fig. 4A). Indeed, a prior transposon mutagenesis screen for deficiencies in hemolytic activity, conducted by Fey et al., also identified SAUSA300_1984 (mroQ) to be a gene important for Hla production (64). Consistent with these observations, the $\triangle m r o Q$ and $\Delta a g r$ mutants exhibited significantly reduced hemolytic activity compared to the WT and $\triangle m r o Q+m r o Q$ strains (Fig. 4B), and both strains were similarly
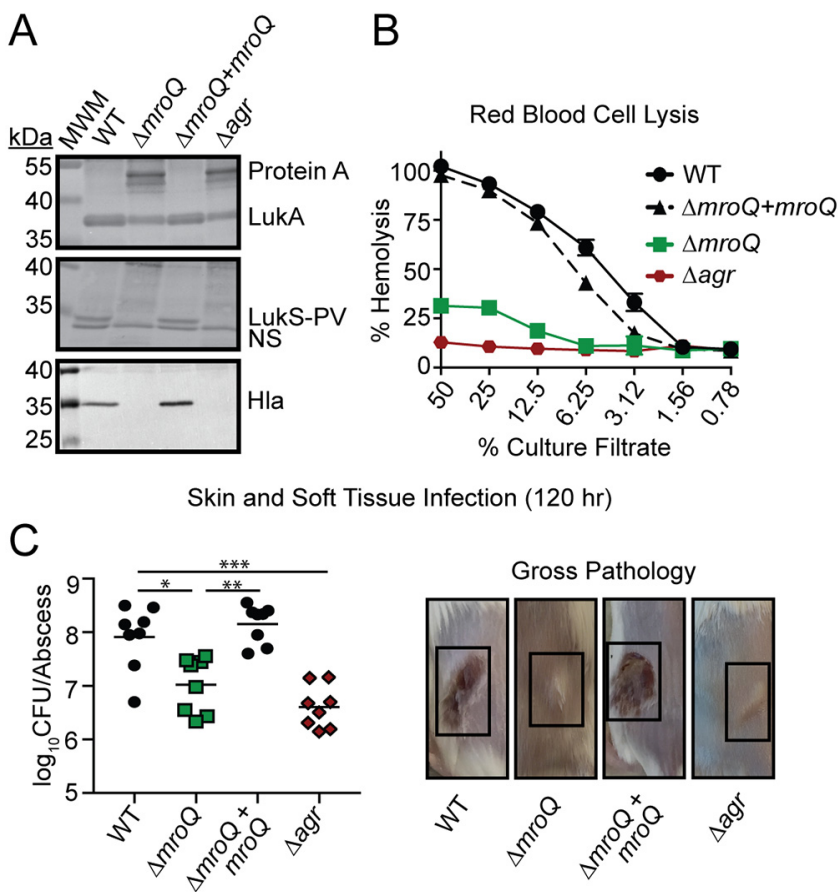

FIG 4 MroQ contributes to Agr function. (A) LukA, LukS-PV, and Hla immunoblots of TCA-precipitated exoproteins from WT, $\triangle m r o Q, \Delta m r o Q+m r o Q$, and $\triangle a g r$ strains. Protein A levels were detected based upon binding of anti-LukA antibody to protein A. MWM, molecular weight marker; NS, nonspecific band. (B) Rabbit red blood cell lysis of cell-free culture filtrates derived from WT, $\Delta m r o Q, \Delta m r o Q+m r o Q$, and $\Delta$ agr strains. (C) (Left) Bacterial burden in skin abscesses of mice at $120 \mathrm{~h}$ postinfection with the WT $(n=8), \Delta m r o Q(n=8), \Delta m r o Q+m r o Q(n=8)$, and $\Delta a g r(n=8)$ strains. $P$ values were determined by a nonparametric one-way ANOVA (Kruskal-Wallis test) with Dunn's posttest. ${ }^{*}, P<0.05 ;{ }^{* *}, P<0.01 ;{ }^{* * *}$, $P<0.001$. (Right) Representative images of skin abscesses at $120 \mathrm{~h}$ postinfection with the WT, $\Delta m r o Q$, $\Delta m r o Q+m r o Q$, and $\Delta a g r$ strains are shown. Hemolysis assay data are from one of at least three experiments conducted in triplicate. Means \pm SD are shown $(n=3)$. 
A

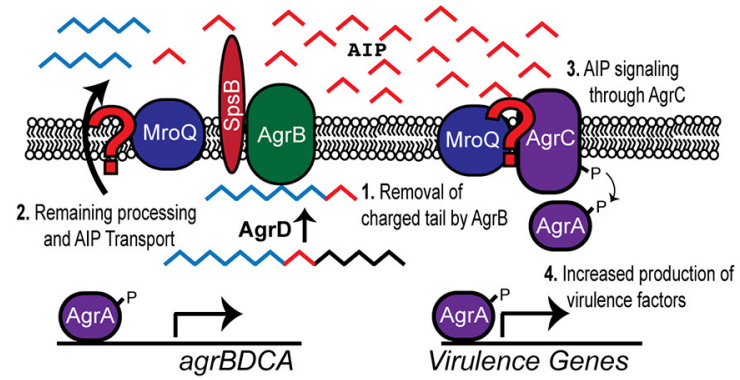

B

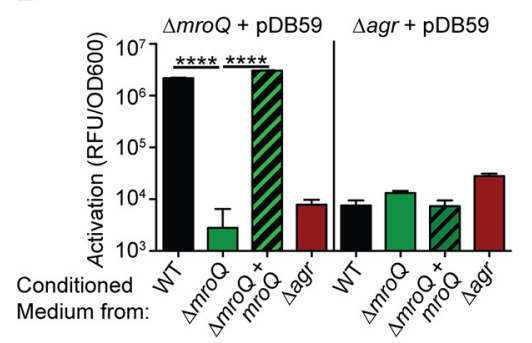

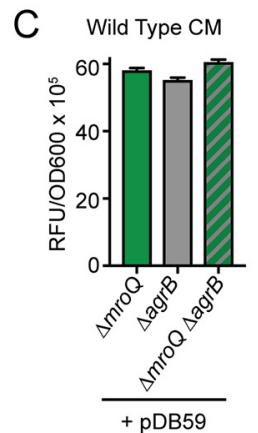

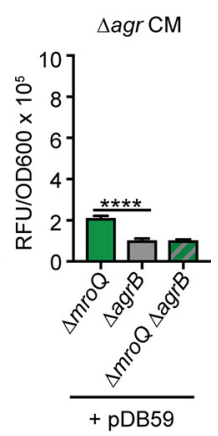

E

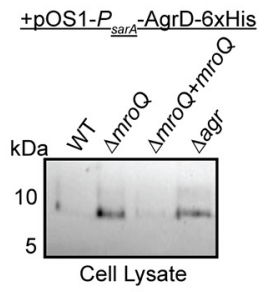

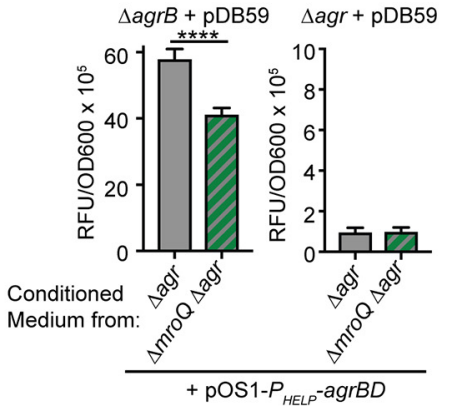

FIG 5 Interrogating the effects of MroQ on Agr peptide processing or signaling. (A) Model depicting the potential locations where MroQ might facilitate Agr function. We propose that MroQ functions at the level of the peptide-processing module (AgrBD) or at the level of the membrane-embedded histidine kinase (AgrC). (B) P3-gfp (pDB59) promoter activation (relative fluorescence units $[\mathrm{RFU}] / \mathrm{OD}_{600}$ ) in the $\triangle m r o Q$ and $\triangle a g r$ strains upon addition of conditioned medium from the WT, $\triangle m r o Q, \triangle m r o Q+m r o Q$, and $\triangle a g r$ strains. (C) P3-gfp/pDB59 promoter activation $\left(\mathrm{RFU} / \mathrm{OD}_{600}\right)$ in the $\triangle m r o Q, \triangle a g r B$, and $\triangle m r o Q \Delta a g r B$ strains upon addition of conditioned medium (CM) from the WT and $\triangle a g r$ strains. (D) Whole-cell lysates of the WT, $\triangle m r o Q, \Delta m r o Q+m r o Q$, and $\Delta a g r$ strains constitutively expressing AgrD- $6 \times$ His (pOS1- $P_{\text {sarA }}$-agrD-6 $\times$ His) followed by immunoblotting with anti-His monoclonal antibody to detect full-length (unprocessed) AgrD. (E) P3-gfp/pDB59 promoter activation (RFU/OD ${ }_{600}$ ) in $\triangle a g r B$ and $\triangle a g r$ strains upon addition of conditioned medium from the $\triangle a g r$ and $\triangle a g r \Delta m r o Q$ strains constitutively expressing agrBD/pOS1-P HELP-agrBD. ${ }^{* * *}, P<0.0001$ by one-way ANOVA with Tukey's posttest (C) and a two-tailed $t$ test (E). The data shown are from one of at least three experiments conducted in triplicate. Means \pm SD are shown $(n=3)$.

attenuated in a murine intradermal infection model (Fig. 4C). In summary, MroQ appears to be required for Agr function in some unknown way.

A $\triangle$ mroQ mutant is compromised for AIP processing or export. MroQ is a hypothetical type II CAAX metalloprotease. Despite the clear connections between Agr and $S$. aureus pathobiology, there exist key gaps in our knowledge of the mechanics of Agr system activation (Fig. 5A) $(5,65)$. Most notably, (i) the complete range of proteins needed for maturation of AgrD has not been fully elucidated, (ii) a dedicated transporter for AIP or its leader peptide has not been conclusively identified, and (iii) differential processing of AIP variants I to IV has not been investigated. We wondered if the function of MroQ within the Agr system might be to facilitate processing and/or export of the AgrD precursor peptide to generate AIP or if it promotes the function of the histidine kinase AgrC in a manner similar to that of SpdC and WalK (Fig. 5A). To test these possibilities, we first introduced a reporter plasmid that drives the expression of green fluorescent protein (GFP) via an AgrA-regulated promoter known as P3 (pDB59P3-gfp) into $\triangle m r o Q$ and $\triangle a g r$ mutant strains (66). We collected conditioned medium (CM) from early-stationary-phase cultures (in which AIP production is high) of the WT, $\Delta m r o Q, \Delta m r o Q+m r o Q$, and $\Delta a g r$ strains and applied them to the reporter strains, followed by measurement of GFP fluorescence. Conditioned medium derived from all strains tested on the $\triangle a g r / p D B 59-P 3-g f p$ reporter strain did not induce promoter activation (Fig. 5B). This was expected because the $\Delta a g r$ mutant lacks all components of the Agr system, including those that transmit the AIP signal (AgrC and AgrA). In 
contrast, when conditioned medium from the WT or $\triangle m r o Q+m r o Q$ strains was added to the $\Delta m r o Q / p D B 59-P 3-g f p$ reporter strain, we observed a significant increase in fluorescence intensity, indicating that the AgrC-AgrA signaling axis is intact and able to recognize AIP. However, conditioned medium from the $\triangle m r o Q$ and $\triangle a g r$ mutants was unable to induce $P 3$ promoter activity in this reporter strain background (Fig. $5 \mathrm{~B}$ ). Similarly, no difference in the ability to transmit the signal through AgrC and AgrA was seen by introduction of the pDB59-P3-gfp reporter into the $\triangle$ agrB and $\triangle a g r B \triangle m r o Q$ strains, followed by the addition of CM derived from WT S. aureus (Fig. 5C). These data suggest that the Agr system defect in the $\triangle m r o Q$ mutant does not occur at the level of AgrC or affect its ability to propagate a signal to AgrA.

The absence of a clear effect of MroQ on AgrC signaling led us to interrogate whether or not MroQ affects AgrD protein processing/export. We generated a plasmid that expresses AgrD- $6 \times$ His under the control of a constitutive promoter (pOS1- $P_{\text {sarA }}{ }^{-}$ agrD-6 $\times$ His) $(67,68)$. The plasmid was introduced into the WT, $\triangle m r o Q, \Delta m r o Q+m r o Q$, and $\Delta a g r$ strains. AgrD accumulates when AgrB peptidase activity is compromised, indicating that processing of AgrD by AgrB precedes export (3, 27-30). We hypothesized that if MroQ is involved in promoting an AgrD processing event similar to that of AgrB, then we should detect full-length AgrD-6 $\times$ His in the $\triangle m r o Q$ mutant. Indeed, full length AgrD- $6 \times$ His was detectable when it was expressed in the $\Delta m r o Q$ and $\Delta a g r$ strains (Fig. 5D). To further determine if MroQ is involved in regulating AgrBD functions related to AIP processing/export, we generated a plasmid that constitutively expresses agrBD driven by the synthetic promoter $P_{\text {HELP }}$ and introduced this plasmid (pOS1- $P_{\text {HELP }}$ agrBD) into $\triangle a g r$ or $\triangle a g r \triangle m r o Q$ strains followed by determination of whether or not conditioned medium derived from these strains was able to activate the pDB59-P3-gfp reporter in a $\triangle a g r B$ or $\triangle a g r$ mutant background. We found that conditioned medium derived from the $\triangle a g r \Delta m r o Q / p O S 1-P_{\text {HELP }}$-agrBD strain exhibited a $30 \%$ reduction in $P 3$ promoter activity compared to that of conditioned medium derived from the $\triangle a g r /$ pOS1- $P_{\text {HELP }}$-agrBD strain (Fig. 5E). These data support the hypothesis that MroQ plays a role in promoting the functionality or stability of the AgrB-AgrD peptide processing/ export axis of the Agr system.

Conserved active-site amino acids are required for MroQ regulation of the Agr system. The type II CAAX protease family of enzymes is conserved in both prokaryotes and eukaryotes. In eukaryotes, proteolytic activity occurs at a CAAX motif on the C-terminal end of target proteins, ultimately leading to lipidation. In bacteria, the functions of the CAAX protease family members are not as clear, but some proteins in this family use proteolytic activity to confer immunity against bacteriocins (69), while others engage in intramembrane proteolysis events to promote adaptive traits $(52,70)$. Of the three additional characterized CAAX protease enzymes in S. aureus (SpdA, SpdB, and $\mathrm{SpaC}$ ), it is known that the conserved active-site glutamate of SpdC does not appear to be required for function (57). This is also true for the Abx1 enzyme of group B Streptococcus (59). Thus, the CAAX proteases of bacteria appear to have diverse functions, some of which depend on proteolytic activity and others of which do not. To test if the active site of MroQ is required to promote AgrBD activity, we introduced mutations into the conserved CAAX protease amino acid residues within the EEXXXR and FXXXH motifs previously determined to be required for enzymatic activity in a range of type II CAAX proteases $(50,52,69,71,72)$. Alanine substitutions were introduced at E141, E142, and H180, followed by expression of point mutations in a single copy under the control of the mroQ native promoter in S. aureus $\triangle m r o Q$ (Fig. $6 \mathrm{~A}$ ). As evidenced by immunoblot analysis, the expression of MroQ(E141A) was unable to complement alpha toxin secretion defects, whereas the MroQ(E142A) and MroQ (H180A) mutants exhibited some restoration in alpha toxin production by immunoblot analysis, with the MroQ(E142A) strain supernatant containing larger amounts of alpha toxin than the MroQ(H180A) strain supernatant (Fig. 6B). The observed differences in alpha toxin levels by immunoblot analysis were recapitulated in hemolytic activity assays where the MroQ(E142A) strain exhibited a partial restoration of hemolytic activity on rabbit red blood cells (RBCs) but the MroQ(E141A) and $\operatorname{MroQ}(\mathrm{H} 180 \mathrm{~A})$ strains 

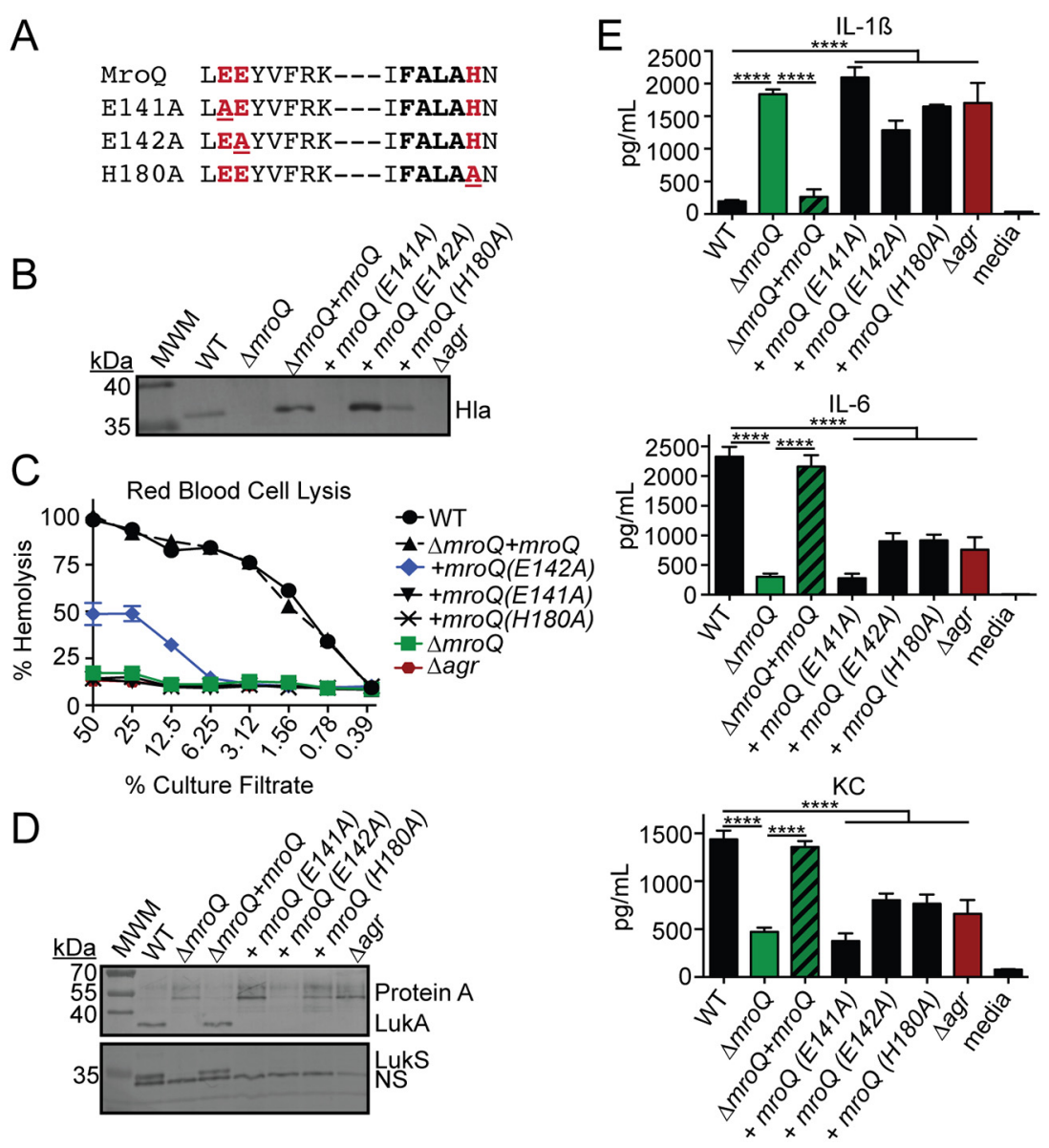

FIG 6 MroQ active-site residues are required for regulation of Agr by MroQ. (A) Amino acid sequences of the EEXXXR and FXXXH motifs that comprise the type II CAAX protease active site. The locations of site-directed amino acid substitutions are underlined. (B) Hla immunoblots of TCA-precipitated exoproteins from the WT, $\Delta m r o Q, \Delta m r o Q+m r o Q, \Delta m r o Q+m r o Q(E 141 A), \Delta m r o Q+m r o Q(E 142 A), \Delta m r o Q+$ mroQ $(H 180 A)$, and $\triangle a g r$ strains. (C) Rabbit red blood cell lysis of cell-free culture filtrates derived from the WT, $\Delta m r o Q, \Delta m r o Q+m r o Q, \Delta m r o Q+m r o Q(E 141 A), \Delta m r o Q+m r o Q(E 142 A), \Delta m r o Q+m r o Q(H 180 A)$, and $\triangle a g r$ strains. (D) LukA and LukS-PV immunoblots of TCA-precipitated exoproteins from the WT, $\Delta m r o Q, \Delta m r o Q+m r o Q, \Delta m r o Q+m r o Q(E 141 A), \Delta m r o Q+m r o Q(E 142 A), \Delta m r o Q+m r o Q(H 180 A)$, and $\triangle a g r$ strains. Protein A levels were detected based upon the binding of anti-LukA antibody to protein $A$. MWM, molecular weight marker; NS, nonspecific band. (E) IL-1 $\beta$, IL-6, and KC production by BMM after addition of supernatant from the WT, $\Delta m r o Q, \Delta m r o Q+m r o Q, \Delta m r o Q+m r o Q(E 141 A), \Delta m r o Q+$ $m r o Q(E 142 A), \triangle m r o Q+m r o Q(H 180 A)$, and $\triangle$ agr strains grown in TSB. ${ }^{* * *}, P<0.0001$ by one-way ANOVA with Tukey's posttest. The data shown are from one of at least three experiments conducted in triplicate. Means \pm SD are shown $(n=3)$.

did not (Fig. 6C). Consistent with the observed effects on alpha toxin secretion and hemolytic activity, MroQ(E142A) partially complemented protein A production defects (Fig. 6D). In contrast, none of the three mutations restored LukS or LukA production to an observable degree by immunoblot analysis, and the MroQ point mutations failed to complement changes in macrophage activation caused by supernatant derived from a $\triangle m r o Q$ mutant (Fig. $6 \mathrm{D}$ and E). Together, these data suggest that conserved amino acids implicated in type II CAAX protease activity are important for the effects of MroQ on AgrBD function. Residue E141 is required for MroQ function, whereas residues E142 and $\mathrm{H} 180$ promote optimal activity.

Investigation of the role of MroQ amino acid residues E141, E142, and $\mathrm{H} 180$ in Agr-mediated gene expression and virulence. We next sought to determine the extent to which $\triangle m r o Q$ mutant strains expressing MroQ(E141A) $[\Delta m r o Q+$ MroQ $(\mathrm{E} 141 \mathrm{~A})], \operatorname{MroQ}(\mathrm{E} 142 \mathrm{~A})[\Delta m r o Q+\operatorname{MroQ}(\mathrm{E} 142 \mathrm{~A})]$, and $\operatorname{MroQ}(\mathrm{H} 180 \mathrm{~A})[\Delta m r o Q+$ MroQ $(E 180 A)]$ alter gene expression and pathogenesis. We first conducted $P 3$ promoter 
A

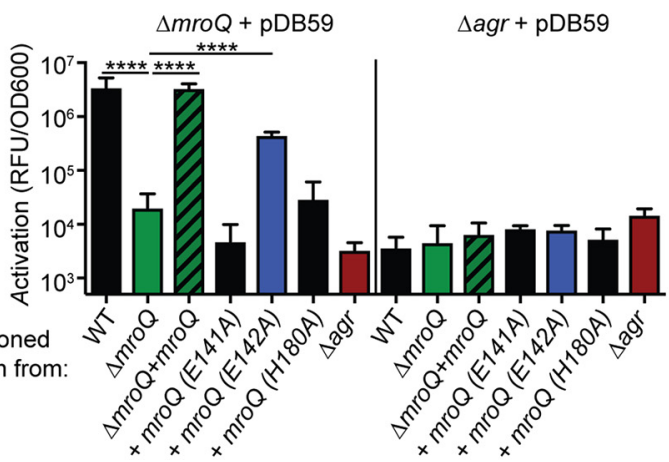

B Skin and Soft Tissue Infection (120 hr)

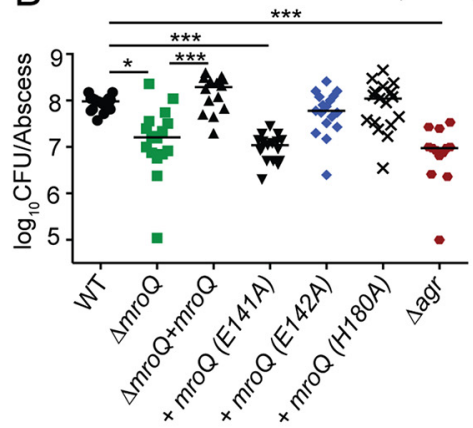

FIG 7 MroQ amino acid substitution E141A is required for Agr activation and full virulence. (A) P3-gfp (pDB59) promoter activation (relative fluorescence units $[R F U] / O_{600}$ ) in $\triangle m r o Q$ and $\triangle a g r$ strains upon addition of conditioned medium from the WT, $\triangle m r o Q, \Delta m r o Q+m r o Q, \Delta m r o Q+m r o Q(E 141 A), \Delta m r o Q+m r o Q(E 142 A)$, $\triangle m r o Q+m r o Q(H 180 A)$, and $\triangle a g r$ strains. The data shown are from one of at least three experiments conducted in triplicate. Means \pm SD are shown $(n=3)$. ${ }^{* * *}, P<0.0001$ by one-way ANOVA with Tukey's posttest. (B) Bacterial burden in skin abscesses of mice at 5 days postinfection with the WT $(n=16), \Delta m r o Q(n=16), \Delta m r o Q+m r o Q$ $(n=14), \Delta m r o Q+\operatorname{mroQ}(E 141 A)(n=17) \Delta m r o Q+\operatorname{mroQ}(E 142 A)(n=17), \Delta m r o Q+\operatorname{mroQ}(H 180 A)(n=17)$, and $\operatorname{\Delta agr}(n=16)$ strains. $P$ values were determined by a nonparametric one-way ANOVA (Kruskal-Wallis Test) with Dunn's posttest. *, $P<0.05$; ${ }^{* *}, P<0.001$.

activation analyses to evaluate whether or not the generation and release of functional AIP occurs in strains expressing each point mutation. As anticipated, conditioned medium derived from the $\Delta m r o Q+M r o Q(E 141 A)$ and $\Delta m r o Q+M r o Q(H 180 A)$ strains was unable to appreciably activate the P3-gfp promoter fusion above background levels when applied to the $\triangle m r o Q / p D B 59$ reporter strain (Fig. 7A). In contrast, conditioned medium derived from the $\triangle m r o Q+\operatorname{MroQ}(\mathrm{E} 142 \mathrm{~A})$ strain led to partial activation with a greater than 10-fold increase in fluorescence intensity compared to background levels (Fig. 7A). When the $\triangle m r o Q+\operatorname{MroQ}(\mathrm{E} 141 \mathrm{~A}), \Delta m r o Q+\operatorname{MroQ}(\mathrm{E} 142 \mathrm{~A})$, and $\triangle m r o Q+$ $\operatorname{MroQ}(\mathrm{H} 180 \mathrm{~A})$ strains were used in an intradermal infection model, we found that the $\Delta m r o Q+\operatorname{MroQ}(\mathrm{E} 141 \mathrm{~A})$ strain exhibited a 10 -fold reduction in the number of CFU, similar to a $\triangle m r o Q$ and $\triangle a g r$ mutant. In contrast, the $\triangle m r o Q+M r o Q(E 142 A)$ and $\Delta m r o Q+M r o Q(H 180 A)$ strains restored infection to nearly WT levels (Fig. 7B). Thus, MroQ(E141A) appears to be the most crucial active-site mutation, as it is necessary for MroQ function in vitro and in vivo, whereas MroQ(E142A) and MroQ(H180A) confer nearly normal virulence characteristics during skin and soft tissue infection, an outcome consistent with their partial restoration of in vitro defects.

\section{DISCUSSION}

Many Gram-positive pathogens use small-peptide signaling pathways to control the expression of virulence genes. In this work, we present the discovery of a membraneembedded protease that plays a major role in promoting the function of the Agr system of S. aureus. Our data suggest that the putative type II CAAX peptidase SAUSA300_1984 (MroQ) directly interfaces with the Agr system to promote virulence factor gene expression and pathogenesis in a murine skin and soft tissue infection model. Unlike other type II CAAX proteases of S. aureus and group B Streptococcus $(57,59)$, MroQ requires its conserved active-site amino acids to confer normal functionality to the Agr system. Our studies to probe the location in the Agr pathway where MroQ acts indicate that the AgrC/A signaling axis remains functional and that the AgrBD axis, involved in peptide maturation, is likely compromised. Together, these findings expand the view of peptide-based signaling in $S$. aureus and highlight a newly uncovered regulatory input into virulence factor gene expression that dramatically affects virulence outcomes. Gram-positive pathogens of urgent clinical importance, including Clostridioides difficile and Enterococcus faecalis, as well as significant threats to food safety, such as Listeria monocytogenes, each harbor Agr systems that contribute to disease (73-79). Thus, this work provides insights into alternative pathways of regulation of the Agr system that may extend to other Gram-positive microbes of clinical importance. 
Our studies have determined that the secreted factors derived from either a $\Delta m r o Q$ mutant or a $\Delta$ agr mutant cause the significant release of IL-1 $\beta$ but the release of low levels of other inflammatory cytokines and chemokines from primary murine macrophages in culture (Fig. 1). The production of the inflammatory cytokine IL-1 $\beta$ in superficial tissues is known to be critical for controlling skin and soft tissue infection caused by $S$. aureus (80-84). In contrast, the production of IL-1 $\beta$ during systemic infection is associated with increased immunopathology $(85,86)$. Agr-defective isolates of $S$. aureus are routinely isolated from patients with bacteremia (65). The reason that these Agr-defective isolates arise and their association with morbidity in bacteremia are not well understood; however, the observation is recapitulated in murine infection models, wherein agr mutants persist in deep tissues during bacteremia (87). Some potential mechanisms behind these observations have been proposed, including a role for agr-defective isolates in the development of a persister state, as well as disruption of the optimal immune environment by agr-defective strains (65). Although a $\triangle m r o Q$ mutant did not elicit the increased production of IL-1 $\beta$ compared to the WT at the time points tested in vivo, we postulate that the reduced levels of proinflammatory cytokines and maintenance of IL-1 $\beta$ may be linked to improved disease outcomes (Fig. 2). The possibility that the inflammatory shifts imparted by a loss of Agr functionality might dictate clearance or survival in superficial versus systemic infection is currently being interrogated by our laboratory.

The mechanics of cyclic AIP maturation by S. aureus are not fully understood (5). Generation of AIP absolutely requires C-terminal cleavage and formation of a thiolactone ring by the Agr locus enzyme AgrB (27-30). The events that occur after thiolactone ring formation remain ambiguous but at a minimum must involve additional proteins for proteolytic cleavage and transport $(5,32)$. Our data demonstrate that the putative metalloprotease MroQ does not seem to influence the ability of the histidine kinase AgrC to transmit a signal to AgrA (Fig. 5C). Thus, it does not appear that MroQ directly regulates the activity of AgrC. This observation is different from that for Abx1 from group B Streptococcus or SpdC of S. aureus, which are implicated in the regulation of CovS and WalK histidine kinases, respectively $(58,59)$. These studies used bacterial two-hybrid assays to determine that Abx1 and SpdC interact with WalK and CovS and that deletion or overexpression changes kinase activity. Aside from these physical associations, no additional evidence was provided to describe how each protein mediates its function, but the studies do note that SpdC negatively regulates WalK and that overexpression of Abx1 promotes CovS activity $(58,59)$. Uncoupling agrBD gene expression from its autoregulatory circuit has allowed us to identify a defect in AIP peptide production when MroQ is absent (Fig. 5E). We found that conditioned medium derived from the $\triangle a g r / p O S 1-P_{\text {HELP }}$-agrBD strain was better able to activate a P3-gfp reporter than conditioned medium derived from the $\triangle a g r \Delta m r O Q / p O S 1-P_{\text {HELP }}$-agrBD strain. Importantly, the absence of MroQ did not eliminate reporter activation, suggesting either that overexpression of agrBD can compensate or that MroQ activity on AgrBD is not essential for peptide maturation/release; rather, it improves its efficiency in some way. Thus, MroQ appears to behave differently from Abx1 and SpdC, where it acts to promote the functionality of the peptide maturation module of Agr, and is important for the optimal generation or export of AIP in the type I Agr MRSA strain LAC. We do not yet know precisely how MroQ mediates its effects on the AgrBD module; however, a $\triangle m r o Q$ mutant does not release appreciable amounts of active AIP (Fig. 5 and 7) and harbors increased amounts of unprocessed cytosolic AIP (Fig. 5D). It is notable that although a $\triangle m r o Q$ mutant closely resembles a $\triangle a g r$ mutant, there appears to be some low-level intrinsic activation of the Agr system in a $\triangle m r o Q$ mutant, as evidenced by $P 3$ promoter activity that rises above the levels in a $\triangle a g r$ mutant (Fig. $5 \mathrm{C}$ and 7A). This observation indicates that mature AIP is at least capable of being produced by a $\triangle m r o Q$ mutant, though at low levels. Taking these findings together, we propose that MroQ promotes efficient AgrD proteolytic processing, transport, or both. This may occur through direct effects on AgrB function or on the AgrD peptide itself. We are currently exploring these possibilities. 
S. aureus strains encode one of four allelic variants of AIP, all of which are capable of causing clinical disease in humans (36-40). Our data indicate that MroQ is critical for the Agr activity of a type I strain. AgrB, the protease that cleaves the C terminus of AgrD, has considerable sequence variability among Agr types, rendering C-terminal cleavage specific to the four Agr groups $(3,30,33)$. There is negligible sequence variation at the amino acid level for MroQ in strains that harbor each of the four Agr alleles (data not shown). Therefore, we suspect either that the activity of MroQ on the Agr system is broad and not influenced by Agr type or that alternative enzymes, perhaps other CAAX proteases, modulate the functions of different Agr types. Given the strict dependency on the length and amino acid composition of the N-terminal tails of AIP for signaling and given that precise peptide cleavage at the $\mathrm{N}$ terminus is a requisite for activity, we favor the possibility that additional peptidases may promote the full maturation or export of these AIP sequence variants (39).

One important difference in the function of MroQ compared to that of other type II CAAX proteases noted in S. aureus is that conserved active-site residues appear to be important for the activity of MroQ but not for that of the CAAX protease SpdC or group B Streptococcus Abx1 $(57,59)$. This represents an additional departure from the models put forth for these CAAX proteases and suggests that MroQ may alternatively function in a way that is similar to that of proteases whose activities involve peptide hydrolysis or intramembrane proteolysis $(50,52,69,71,72)$. Thus far, we know that the glutamate at position 141 is critical for MroQ function, whereas mutations of glutamate at position 142 and the histidine at position 180 do not confer complete null phenotypes. In other type II CAAX protease family members, the second glutamic acid in the EEXXXR motif is usually essential for activity, an observation that is contrary to what was observed for MroQ (50). While the E142A and H180A mutations conferred a partial restoration of Agr activity, only the mutant with the E141A point mutation was attenuated in vivo to the same level as a $\triangle m r o Q$ or $\triangle a g r$ mutant during skin and soft tissue infection. This outcome suggests that the partial Agr activity conferred by expression of MroQ(E142A) and $\operatorname{MroQ}(\mathrm{H} 180 \mathrm{~A})$, but not that conferred by expression of $\mathrm{MroQ}(\mathrm{E} 141 \mathrm{~A})$, is sufficient to confer normal infection kinetics.

Altogether, this work has expanded our understanding of the regulatory inputs that dictate cyclic peptide quorum sensing in S. aureus. Our studies represent an expansion of the Agr regulatory circuit that may have broad impacts on therapeutic design for noncomplicated infection $(12,14,88-90)$. Further, the work highlights the complexities of peptide-based signaling and the adaptive traits that promote virulence in S. aureus. Our knowledge of the activities of proteins from the type II CAAX protease family in Gram-positive pathogens remains in its infancy. This work adds to the growing compendium of work on proteins in this protein class and their diverse range of functions, some of which are crucial for Gram-positive bacterial virulence.

\section{MATERIALS AND METHODS}

Bacterial strains and culture conditions. S. aureus LAC (AH-1263) was used as the wild-type (WT) strain for the experiments in this study. LAC (AH-1263) is an S. aureus USA300 clinical isolate cured of its plasmids (91). All other bacterial strains used in this work are described in Table 1. Most recombinant plasmids were passaged through Escherichia coli DH5 $\alpha$ before propagation in S. aureus. When constructing complementation plasmids harboring the $m r o Q$ gene, we found that $m r o Q$ exhibited signs of toxicity in $E$. coli, resulting in a high frequency of secondary mutations in the coding sequence. As an alternative, E. coli $\mathrm{BH} 10 \mathrm{C}$ was used as a host strain; $\mathrm{BH} 10 \mathrm{C}$ reduces the copy number of plasmids to nearly single-copy levels to limit the abundance of potentially toxic genes in $E$. coli and reduces the likelihood of mutations (92). After passage through E. coli, S. aureus RN4220 and RN9011 (RN4220/pRN7023) (62) were used as intermediate strains, followed by electroporation or transduction into AH-1263 or its isogenic mutant derivatives. All E. coli strains were grown in lysogeny broth (LB; Amresco), while $S$. aureus strains were grown in either tryptic soy broth (TSB; Criterion) or RPMI medium (Corning) supplemented with $1 \%$ Casamino Acids (Amresco) and $2.4 \mathrm{mM}$ sodium bicarbonate (Amresco). When necessary, the media were supplemented with the following antibiotics at the indicated concentrations: ampicillin (Amp) (GoldBio), $100 \mu \mathrm{g} / \mathrm{ml}$; erythromycin (Erm) (Amresco), $5 \mu \mathrm{g} / \mathrm{ml}$; chloramphenicol (Cm) (Amresco), $10 \mu \mathrm{g} / \mathrm{ml}$; anhydrous tetracycline (AnTet) (Acros Organics), $1 \mu \mathrm{g} / \mathrm{ml}$; and tetracycline (Tet) (Amresco and Acros Organics), $10 \mu \mathrm{g} / \mathrm{ml}$. Cadmium chloride (Alfa Aesar) was used at 0.1 to $0.3 \mathrm{mM}$ to select for pJC1111 transductants. Bacterial growth was monitored using a Genesys 10S UV-visible spectrophotometer by measuring the culture optical density at $600 \mathrm{~nm}\left(\mathrm{OD}_{600}\right.$; Thermo). 
TABLE 1 Strains used in this study

\begin{tabular}{|c|c|c|c|}
\hline Strain & Description & Designation & Source or reference \\
\hline $\mathrm{AH}-1263$ & S. aureus USA300 strain LAC, plasmid cured & LAC (WT) & 91 \\
\hline $\mathrm{DH} 5 \alpha$ & E. coli strain for recombinant plasmids & $\mathrm{DH} 5 \alpha$ & \\
\hline $\mathrm{BH} 10 \mathrm{C}$ & $\begin{array}{l}\text { E. coli strain that restricts the plasmid copy } \\
\text { number for complementation of } m r o Q\end{array}$ & $\mathrm{BH} 10 \mathrm{C}$ & 92 \\
\hline RN4220 & Restriction-deficient $S$. aureus & RN4220 & 96 \\
\hline RN9011 & RN4220/pRN7023 expressing SaPI1 integrase & RN9011 & 62 \\
\hline FA-S922 & $\mathrm{AH}-1263$ with an in-frame deletion of $\mathrm{mroQ}$ & $\Delta m r o Q$ mutant & This work \\
\hline FA-S995 & FA-S922 transduced with $\Delta$ agr::tet mutation & $\Delta m r o Q \Delta a g r:: t e t$ mutant & This work \\
\hline FA-S1732 & $\mathrm{AH}-1263$ with an in-frame deletion of $\operatorname{agr} B$ & $\Delta a g r B$ mutant & This work \\
\hline FA-S1736 & FA-S922 containing an in-frame deletion of $a g r B$ & $\Delta a g r B \Delta m r o Q$ mutant & This work \\
\hline $\mathrm{AH}-\mathrm{E} 462$ & $\begin{array}{l}\text { E. coli containing reporter plasmid pDB59 with } \\
\text { gfp expression driven by the } P 3 \text { promoter }\end{array}$ & & 66,97 \\
\hline FA-S945 & FA-S922 with GFP reporter plasmid pDB59 & $\Delta m r o Q / p D B 59$ mutant & This work \\
\hline FA-S1146 & FA-S922 containing pOS1- $P_{\text {sarA }}$-sod ${ }_{\mathrm{RBS}}-$ agrD- $6 \times \mathrm{His}$ & $\Delta m r o Q / p O S 1-P_{\text {sarA }}-a g r D-6 \times$ His mutant & This work \\
\hline FA-S1147 & FA-S1008 containing pOS1- $P_{\text {sarA }}$-sod ${ }_{\text {RBS }}-a g r D-6 \times$ His & $\triangle a g r / p O S 1-P_{\text {sarA }}-a g r D-6 \times$ His mutant & This work \\
\hline FA-S1265 & FA-S982 containing pOS1- $P_{\text {sarA }}$-Sod ${ }_{\mathrm{RBS}}-$ agrD- $6 \times \mathrm{His}$ & $\Delta m r o Q+m r o Q / p O S 1-P_{\text {sarA }}$-agrD-6 $\times$ His mutant & This work \\
\hline FA-S1841 & FA-S922 containing pJC1111-mroQ(E141A) & $\Delta m r o Q+m r o Q(E 141 A)$ mutant & This work \\
\hline FA-S1898 & FA-S922 containing pJC1111-mroQ(E142A) & $\Delta m r o Q+m r o Q(E 142 A)$ mutant & This work \\
\hline FA-S1837 & FA-S922 containing pJC1111-mroQ(H180A) & $\Delta m r o Q+m r o Q(H 180 A)$ mutant & This work \\
\hline FA-S2012 & FA-S1008 containing pOS1-P $P_{\text {HELP }}$-agrBD & $\triangle a g r / p O S 1-P_{H E L P}-a g r B D$ mutant & This work \\
\hline FA-S2013 & FA-S995 containing pOS1- $P_{\text {HELP }}$-agrBD & $\Delta$ agr $\Delta m r o Q / p O S 1-P_{\text {HELP }}$-agrBD mutant & This work \\
\hline
\end{tabular}

Molecular genetic techniques. To isolate genomic DNA from $S$. aureus, cultures were grown overnight in $5 \mathrm{ml} \mathrm{TSB}$ at $37^{\circ} \mathrm{C}$ with shaking at $200 \mathrm{rpm}$. Bacteria $(1.5 \mathrm{ml})$ were pelleted by centrifugation and resuspended in $200 \mu \mathrm{l}$ of TSM buffer $(50 \mathrm{mM}$ Tris, $0.5 \mathrm{M}$ sucrose, $10 \mathrm{mM} \mathrm{MgCl} 2[\mathrm{pH} 7.5])$ and $2.5 \mu \mathrm{l}$ of a lysostaphin (Ambi Products) stock ( $2 \mathrm{mg} / \mathrm{ml}$ ) to achieve a final concentration of $25 \mu \mathrm{g} / \mathrm{ml}$. Samples were incubated at $37^{\circ} \mathrm{C}$ for $15 \mathrm{~min}$ to digest the cell wall of $\mathrm{S}$. aureus, followed by centrifugation at $14,000 \mathrm{rpm}$ for $5 \mathrm{~min}$ to pellet the bacteria. The supernatants were discarded, and the genomic DNA was isolated using a Wizard Genomic DNA purification kit (Promega). PCR was performed in a FlexID Mastercycler (Eppendorf) using Phusion High-Fidelity DNA polymerase (New England Biolabs) or GoTaq DNA polymerase (Promega) and deoxynucleoside triphosphates (Quanta BioSciences). For all PCRs, oligonucleotides were ordered from Eurofins (Table 2). Electrophoresis of DNA samples was performed in $0.8 \%$ agarose (Amresco) gels. DNA digestions were performed using the restriction endonucleases Xhol, BamHl, EcoRl, Kpnl, Xbal, Sacl, and Pstl (New England Biolabs) following the manufacturer's suggested protocols, and all digested plasmids were subsequently treated with shrimp alkaline phosphatase (Amresco). Ligations were performed using T4 DNA ligase (New England Biolabs), and the ligation mixtures were incubated in an Eppendorf ThermoMixer at $16^{\circ} \mathrm{C}$ overnight. When necessary, PCR purification and DNA gel extraction were carried out using Qiagen QIAquick kits.

To isolate plasmids from S. aureus, 5 -ml overnight cultures of bacteria were grown in TSB at $37^{\circ} \mathrm{C}$ with shaking at $200 \mathrm{rpm}$. On the next day, the bacteria were pelleted by centrifugation at 4,200 rpm for $15 \mathrm{~min}$ and resuspended in $400 \mu \mathrm{l}$ of TSM buffer containing $20 \mu \mathrm{l}$ of lysostaphin stock solution $(2 \mathrm{mg} / \mathrm{ml})$ to achieve a final concentration of $0.1 \mathrm{mg} / \mathrm{ml}$. Samples were incubated for $10 \mathrm{~min}$ at $37^{\circ} \mathrm{C}$ to digest the cell wall, followed by centrifugation at $13,000 \mathrm{rpm}$ for $2 \mathrm{~min}$ to pellet the bacterial cells. Thereafter, a Qiagen miniprep kit was used to isolate plasmid DNA. DNA was eluted with sterile water in all cases. DNA sequencing was performed by GenScript or Genewiz.

Bacteriophage-mediated generalized transduction. Transduction was used to transfer stably integrated complementation plasmids between strains, as well as to mobilize marked mutations within the S. aureus chromosome ( $\triangle$ agr::tet). S. aureus-specific bacteriophage $\phi 11$ or $80 \alpha$ was used in this study. Donor strains were grown overnight in $3 \mathrm{ml}$ of TSB-LB (1:1) supplemented with $5 \mathrm{mM}$ calcium chloride $\left(\mathrm{CaCl}_{2} ;\right.$ Amresco) and $5 \mathrm{mM}$ magnesium sulfate $\left(\mathrm{MgSO}_{4} ;\right.$ Amresco) at $37^{\circ} \mathrm{C}$ with shaking at $200 \mathrm{rpm}$. On the next day, overnight cultures were diluted 1:100 in $10 \mathrm{ml}$ fresh TSB-LB (1:1) supplemented with $5 \mathrm{mM}$ $\mathrm{CaCl}_{2}$ and $5 \mathrm{mM} \mathrm{MgSO}_{4}$. Samples were grown for $\sim 3 \mathrm{~h}$ at $37^{\circ} \mathrm{C}$ with shaking at $200 \mathrm{rpm}$ until reaching an $\mathrm{OD}_{600}$ of 0.3 to 0.9 . To package donor DNA into transducing phage, $100 \mu \mathrm{l}$ of 10 -fold serial dilutions $\left(10^{-1}\right.$ to $\left.10^{-10}\right)$ of bacteriophage stock in TMG $\left(10 \mathrm{mM}\right.$ Tris, $\mathrm{pH} 7.5,5 \mathrm{mM} \mathrm{MgCl}{ }_{2}, 0.01 \%$ [vol/vol] gelatin) was added to $15-\mathrm{ml}$ conical tubes and incubated with $500 \mu \mathrm{l}$ of the donor $\mathrm{S}$. aureus culture. The phage-bacterium mixture was gently vortexed and incubated at room temperature for $30 \mathrm{~min}$. Melted and cooled CY top agar ( $2.5 \mathrm{ml}$; Casamino Acids, $5 \mathrm{~g} /$ liter; yeast extract, $5 \mathrm{~g} /$ liter; glucose, $5 \mathrm{~g} /$ liter; $\mathrm{NaCl}$, $6 \mathrm{~g} /$ liter; agar, $7.5 \mathrm{~g} /$ liter) supplemented with $5 \mathrm{mM} \mathrm{CaCl}_{2}$ and $5 \mathrm{mM} \mathrm{MgSO}_{4}$ was added to the bacteriumphage mixture and immediately poured onto tryptic soy agar (TSA) plates, followed by incubation 
TABLE 2 Oligonucleotides used in this study

\begin{tabular}{|c|c|}
\hline Name & Sequence \\
\hline MroQ-1 & CCC-GGTACC(Kpnl)-CCATAAATGATAAACCTCCAT \\
\hline MroQ-2 & GTGTGATTCGTITITITATTA-GGCGCC(KasI)-CATAATITTCCTCCAAATATT \\
\hline MroQ-3 & AATATTTGGAGGAAAATTATG-GGCGCC(KasI)-TAATAAAAAAAACGAATCACAC \\
\hline MroQ-4 & CCC-GAGCTC(Sacl)-ATTITAAGCCTTGGCAAATG \\
\hline $37 \mathrm{~F}$ & GGCGGATCCAGCACTATCAGTTAAAACAAT \\
\hline $37 R$ & GGCGAATTCACAAGAAGATAATAAGAAAAG \\
\hline agrB-1 & ATAT-GGTACC(Kpnl)-TAACTCTACTAGCAAATGTTACTC \\
\hline agrB-2 & GTTAAATAATGTATTCATTITACACCACTCTCCTCA \\
\hline agrB-3 & TGAGGAGAGTGGTGTAAAAATGAATACATTATTTAAC \\
\hline agrB-4 & ATAT-GAGCTC(Sacl)-TATTACAAATATACTATCAGAAATTTTGGTG \\
\hline MroQPM-CompF & GGC-CTGCAG(Pstl)-AGCACTATCAGTTAAAACAAT \\
\hline MroQPM-CompR & GGC-TCTAGA(Xbal)-ACAAGAAGATAATAAGAAAA \\
\hline $\operatorname{MroQ}(\mathrm{H} 180 \mathrm{~A})-2$ & AAATTTGAAATCATTGGCTGCTAATGCAAATATTAATG \\
\hline $\operatorname{MroQ}(\mathrm{H} 180 \mathrm{~A})-3$ & CATTAATATTTGCATTAGCAGCCAATGATTTCAAATTT \\
\hline $\operatorname{MroQ}(\mathrm{E} 141 \mathrm{~A})-2$ & 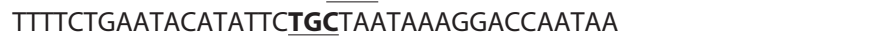 \\
\hline $\operatorname{MroQ}(\mathrm{E} 141 \mathrm{~A})-3$ & TTATTGGTCCTITATTAGCAGAATATGTATTCAGAAA \\
\hline $\operatorname{MroQ}(\mathrm{E} 142 \mathrm{~A})-2$ & ПTाTCTGAATACATATGCTTCTAATAAAGGACCAATAA \\
\hline $\operatorname{MroQ}(\mathrm{E} 142 \mathrm{~A})-3$ & TTATTGGTCCTTATTAGAAGCATATGTATTCAGAAAA \\
\hline phelp-agrBD-1 & ATAT-GTCGAC(Sall)-ATCCCATTATGCTTTGGCA \\
\hline phelp-agrBD-2 & CAATTTATTATCAAAATAATTCAAGGGTTCACTCTCCTTCTA \\
\hline phelp-agrBD-3 & TAGAAGGAGAGTGAAACCCTTGAATTATTTTGATAATAAAATTG \\
\hline phelp-agrBD-4 & ATAT-GAATTC(EcoRI)-TTATTCGTGTAATTGTGTTAAT \\
\hline PsarA-AgrD6 $\times$ His-1 & ATAT-CTGCAG(Pstl)-CTGATATITTGAC \\
\hline PsarA-AgrD6 $\times$ His-2 & AAATAAGTTAAATAATGTATTCAT-AAATAATCATCCTCCTAAGG \\
\hline PsarA-AgrD6 $\times$ His-3 & СCTTAGGAGGATGATTATTT-ATGAATACATTATTTAACTTATTT \\
\hline PsarA-AgrD6 $\times$ His-4 & ATAT-GAATTC(EcoRI)-TTAGTGATGGTGAATGGTGA \\
\hline
\end{tabular}

aUnderlining and boldface indicate locations of nucleotide substitutions.

overnight at $30^{\circ} \mathrm{C}$. On the following day, the phages were harvested from two to three plates with confluent plaques. Bacteriophage stocks were stored at $4^{\circ} \mathrm{C}$.

To transduce plasmids and marked mutations, recipient strains were first grown overnight in $20 \mathrm{ml}$ of TSB-LB (1:1) supplemented with $5 \mathrm{mM} \mathrm{CaCl}_{2}$ at $37^{\circ} \mathrm{C}$. Samples were then centrifuged for $15 \mathrm{~min}$ at maximum speed, the supernatants were discarded, and the bacterial pellets were suspended in $3 \mathrm{ml}$ of CY medium (Casamino Acids, $5 \mathrm{~g}$ /liter; yeast extract, $5 \mathrm{~g} /$ liter; glucose, $5 \mathrm{~g} /$ liter; $\mathrm{NaCl}, 6 \mathrm{~g} /$ liter) supplemented with $5 \mathrm{mM} \mathrm{CaCl}_{2}$. Four infection conditions were set up with either bacteria alone (mock) or 10-fold serial dilutions of bacteria infected with $100 \mu \mathrm{l}$ of a bacteriophage stock containing donor DNA. The tubes were mixed by inverting every $10 \mathrm{~min}$ for $30 \mathrm{~min}$ at room temperature, followed by the addition $40 \mathrm{mM}$ sodium citrate to each tube and incubation for $30 \mathrm{~min}$ at room temperature. The tubes were centrifuged at maximum speed for $5 \mathrm{~min}$ and washed twice in $500 \mu \mathrm{l}$ of CY medium supplemented with $40 \mathrm{mM}$ sodium citrate, followed by resuspension in $200 \mu \mathrm{l}$ of CY medium supplemented with $40 \mathrm{mM}$ sodium citrate and spreading onto $\mathrm{CY}$ agar or TSA plates containing $10 \mathrm{mM}$ sodium citrate and any antibiotics necessary for selection. The plates were placed at $37^{\circ} \mathrm{C}$ overnight. Potential transductants were screened for antibiotic resistance and acquisition of the desired mutations by PCR and DNA sequencing.

Generation of mroQ and agrB in-frame deletion mutants. $m r o Q$ and agrB in-frame deletion mutants were generated using the temperature-sensitive mutagenesis plasmid pIMAY (93). For $m r o Q$, two fragments that correspond to $\sim 500$-bp regions of sequence homology immediately upstream and downstream of mroQ were amplified. Oligonucleotides MroQ-1 and MroQ-2 were used to amplify the region upstream of $m r o Q$, while oligonucleotides MroQ-3 and MroQ-4 were used to amplify the region downstream of mroQ (Table 2). The fragments were joined by splicing by overlap extension (SOEing) PCR using oligonucleotides MroQ-1 and MroQ-4 and subcloned into the multicloning site of pIMAY using restriction endonucleases $\mathrm{Kpnl}$ and Sacl. For agrB, two fragments that correspond to $\sim 500-\mathrm{bp}$ regions of sequence homology immediately upstream and downstream of agrB were amplified. Oligonucleotides agrB-1 and agrB-2 were used to amplify the region upstream of agrB, while oligonucleotides agrB-3 and agrB-4 were used to amplify the region downstream of agrB (Table 2). The fragments were joined by splicing by overlap extension (SOEing) PCR using oligonucleotides agrB-1 and agrB-4 and subcloned into the multicloning site of pIMAY using restriction endonucleases Kpnl and Sacl. Mutagenesis was carried out according to our previously published protocols $(48,49)$. PCR and DNA sequencing analysis were used to determine the successful generation of mutants.

Generation of $\Delta m r o Q+m r o Q, \Delta m r o Q+m r o Q(E 141 A), \Delta m r o Q+m r o Q(E 142 A)$, and $\Delta m r o Q+$ mroQ $(H 180 A)$ complementation strains. A single-copy chromosomal complementation strain driving mroQ expression under its native promoter was constructed using the integrative plasmid pJC1112 (62). The pJC1112-mroQ plasmid was generated by PCR using oligonucleotides 37F and 37R (Table 2). The resulting amplicon was then subcloned into the pJC1112 vector using the EcoRI and BamHI restriction endonucleases, followed by transformation into E. coli BH10C and electroporation into the RN9011 strain, where the plasmid integrates at the Sapl1 site. The integrated complementation vector was then 
transduced into a $\triangle m r o Q$ mutant as described above. Successful introduction of the complementation construct was determined by $\mathrm{PCR}$ and sequencing. To generate complementation strains harboring amino acid substitutions in MroQ catalytic residues, primer MroQPM-CompF was paired with primer MroQ(E141A)-2, MroQ(E142A)-2, or MroQ(H180A)-2 and primer MroQPM-CompR was paired with MroQ(E141A)-3, MroQ(E142A)-3, or MroQ(H180A)-3. The resulting amplicons from these two PCRs were used in a SOEing PCR with primers MroQPM-CompF and MroQPM-CompR, followed by subcloning the product into $\mathrm{pJC1111}$ using the $\mathrm{Xbal}$ and Pstl restriction endonucleases and then transformation into $E$. coli $\mathrm{BH} 10 \mathrm{C}$ and electroporation into the RN9011 strain, where the plasmid integrates at the Sapl1 site. The integrated complementation vector was then transduced into a $\triangle m r o Q$ mutant as described above.

Construction of $\Delta$ agr::tet mutants. A marked deletion mutation of agrBDCA ( $\triangle a g r:$ tet) was transduced into the AH-1263 (WT), $\triangle m r o Q$, and $\triangle a g r B$ strains by bacteriophage-mediated transduction as described above.

Construction of $\mathbf{P 3 - g f p}$ reporter strains. The pDB59 reporter plasmid contains the $P 3$ promoter of the Agr system driving the expression of $g f p$ (56). The plasmid was isolated from $E$. coli and passaged through RN4220, followed by electroporation into the WT, $\Delta m r o Q, \triangle a g r B, \Delta a g r B \Delta m r o Q$, and $\Delta a g r:: t e t$ strains.

Construction of pOS1-P $P_{\text {sarA }}$-agrD-6 $\times$ His expression plasmid. An AgrD-6 $\times$ His expression plasmid was generated by fusing the $P_{\text {sarA }}$ promoter linked to the $S$. aureus superoxide dismutase (sod) ribosomal binding site $\left(\operatorname{sod}_{\mathrm{RBS}}\right)(67,68)$ and to the coding sequence of AgrD harboring a $6 \times \mathrm{His}$ tag on its $\mathrm{C}$ terminus. $P_{\text {sarA }}$-sod ${ }_{\mathrm{RBS}}$ was amplified using primers PsarA-AgrD6 $\times$ His- 1 and PsarA-AgrD6 $\times$ His-2, and agrD-6 $\times$ His was amplified using oligonucleotides PsarA-AgrD6 $\times$ His-3 and PsarA-AgrD6 $\times$ His-4. A SOEing PCR was performed to splice these amplicons together using primers PsarA-AgrD6 $\times$ His- 1 and PsarAAgrD6 $\times$ His-4. The resulting amplicon was cloned into pOS1 using the Pstl and EcoRl restriction endonucleases, and the product was transformed into $\mathrm{DH} 5 \alpha$, passaged through RN4220, and electroporated into the wild-type, $\triangle m r o Q, \triangle m r o Q+m r o Q$, and $\triangle a g r$ isogenic strains.

Construction of pOS1-P $P_{\text {HELP }}$-agrBD plasmid. An agrBD expression plasmid was generated by fusing the $P_{\text {HELP }}$ promoter $(48,49,94)$ to agrBD. $P_{\text {HELP }}$ was amplified using primers phelp-agrBD-1 and phelpagrBD-2, and agrBD was amplified using oligonucleotides phelp-agrBD-3 and phelp-agrBD-4. A SOEing $\mathrm{PCR}$ was performed to splice the resulting amplicons together using primers phelp-agrBD-1 and phelp-agrBD-4. The final amplicon was cloned into pOS1 using the Sall and EcoRI restriction endonucleases, and the resulting plasmid was transformed into E. coli BH10C, passaged through RN4220, and electroporated into the wild-type, $\triangle a g r$, and $\triangle a g r \Delta m r o Q$ isogenic strains.

Whole-cell lysate preparation. Five milliliters of $S$. aureus strains was grown overnight at $37^{\circ} \mathrm{C}$ with shaking at $200 \mathrm{rpm}$. Overnight cultures were diluted 1:100 in $20 \mathrm{ml}$ of fresh medium and allowed to replicate for an additional $8 \mathrm{~h}$ at $37^{\circ} \mathrm{C}$ with shaking at $200 \mathrm{rpm}$. After $8 \mathrm{~h}$, the $\mathrm{OD}_{600}$ was measured and samples were centrifuged at $4,200 \mathrm{rpm}$ for $15 \mathrm{~min}$ to pellet the bacteria. The supernatants were removed, and the bacterial cell pellets were stored at $-80^{\circ} \mathrm{C}$ until use. The pellets were thawed on ice and resuspended in $250 \mu \mathrm{l}$ of phosphate-buffered saline (PBS) supplemented with $1 \mathrm{M} \mathrm{NaCl}$ and $6 \mathrm{M}$ urea (VWR). The resuspended bacteria were then added to screw-cap microcentrifuge lysing tubes (Fisher Scientific) containing $250 \mu \mathrm{l} 0.1$-mm glass cell disruption beads (Scientific Industries, Inc.). Cells were lysed using a Fast Prep-24 5G homogenizer (MP Biomedicals) at speed 5.0 for $20 \mathrm{~s}$ with subsequent incubation on ice for $5 \mathrm{~min}$ and were then disrupted a second time at speed 4.5 for $20 \mathrm{~s}$. Fifty microliters of $6 \times$ sodium dodecyl sulfate (SDS) sample buffer ( $0.375 \mathrm{M}$ Tris, $\mathrm{pH} 6.8,12 \% \mathrm{SDS}, 60 \%$ glycerol, $0.6 \mathrm{M}$ dithiothreitol, $0.06 \%$ bromophenol blue) was added directly to the lysed cells, and the mixture was boiled for $10 \mathrm{~min}$, followed by centrifugation at maximum speed for $15 \mathrm{~min}$ at $4^{\circ} \mathrm{C}$. Samples were stored at $-20^{\circ} \mathrm{C}$ for no longer than a few days.

Exoprotein preparations. S. aureus strains were grown at $37^{\circ} \mathrm{C}$ with shaking at $200 \mathrm{rpm}$ overnight. Overnight cultures were diluted 1:100 in fresh medium and allowed to grow to stationary phase at $37^{\circ} \mathrm{C}$ with shaking at $200 \mathrm{rpm}(\sim 8 \mathrm{~h})$. The $\mathrm{OD}_{600}$ was measured, and samples were centrifuged at $4,200 \mathrm{rpm}$ for $15 \mathrm{~min}$. The supernatants $(1.3 \mathrm{ml})$ were collected in $1.5-\mathrm{ml}$ microcentrifuge tubes and cooled on ice for approximately $30 \mathrm{~min}$, followed by addition of $150 \mu \mathrm{l}$ of $100 \%$ trichloroacetic acid (TCA) and overnight incubation at $4^{\circ} \mathrm{C}$. On the next day, samples were centrifuged at maximum speed for $15 \mathrm{~min}$ at $4^{\circ} \mathrm{C}$ and the supernatants were removed and discarded. Precipitated proteins were washed with $1 \mathrm{ml}$ of $100 \%$ ethanol (Decon Laboratories Inc.) and incubated at $4^{\circ} \mathrm{C}$ for $30 \mathrm{~min}$, followed by a 15 -min spin at maximum speed at $4^{\circ} \mathrm{C}$. The protein pellets were air dried at room temperature for about $1 \mathrm{~h}$, followed by dissolving the pellet in TCA-SDS sample buffer (0.5 M Tris-HCl buffer, 4\% SDS mixed 1:1 with $2 \times$ SDS sample buffer) and boiling for $10 \mathrm{~min}$ before storage at $-20^{\circ} \mathrm{C}$.

Immunoblot analysis for secreted virulence factors. The wild-type, $\triangle m r o Q, \triangle m r o Q+m r o Q$, $\triangle m r o Q+m r o Q(E 141 A), \triangle m r o Q+m r o Q(E 142 A), \triangle m r o Q+m r o Q(H 180 A)$, and $\triangle a g r$ strains were grown in $5 \mathrm{ml}$ of TSB for $8 \mathrm{~h}$ at $37^{\circ} \mathrm{C}$ with shaking at $200 \mathrm{rpm}$, and the supernatants were collected for TCA precipitation as described above. Prior to loading, protein samples were normalized based on the $\mathrm{OD}_{600}$ and subsequently separated by sodium dodecyl sulfate (SDS)-polyacrylamide gel electrophoresis (PAGE) on $12 \%$ polyacrylamide gels at $120 \mathrm{~V}$ in a Quadra Mini-Vertical PAGE/blotting system (CBS Scientific). The resolved proteins were then transferred from the polyacrylamide gels to $0.45-\mu \mathrm{m}$-pore-size polyvinylidene difluoride membranes (Immobilon; Roche) at $200 \mathrm{~V}$ for $1 \mathrm{~h}$. After transfer, the membranes were stored overnight in Tris-buffered saline (TBS)-Tween 20 (TBST; 0.1\% Tween 20 [Amresco] in TBS [Corning]) at $4^{\circ} \mathrm{C}$. Membranes were then blocked in TBST-5\% bovine serum albumin (BSA) (Amresco) for $1 \mathrm{~h}$ while rocking at room temperature. Rabbit anti-LukA $(1: 50,000)$, rabbit anti-LukS-PV $(1: 50,000)$, and rabbit anti-Hla $(1: 50,000)$ antibodies (63) were incubated with the membranes in TBST for $1 \mathrm{~h}$. Although these antibodies recognize LukA, LukS-PV, and $\mathrm{Hla}$, they also permit the detection of protein $\mathrm{A}$ due to 
its binding of the Fc region of antibodies (95). Following incubation with primary antibodies, the membranes were washed three times in TBST for $15 \mathrm{~min}$ and goat anti-rabbit $\lg \mathrm{G}(\mathrm{H}+\mathrm{L})$ conjugated to alkaline phosphatase (Thermo) was added at a 1:5,000 dilution in TBST with 5\% BSA for $1 \mathrm{~h}$. The membranes were washed 3 times in TBST for 15 min each time, and the blots were developed with 5-bromo-4-chloro-3-indoyl-phosphate-nitroblue tetrazolium (BCIP/NBT) color development substrate (VWR).

AIP reporter assays. Reporter strains containing pDB59 (described above) and test strains (from which conditioned medium was collected) were cultured overnight in TSB supplemented with $\mathrm{Cm}$ at $37^{\circ} \mathrm{C}$ with shaking at $200 \mathrm{rpm}$. On the next day, samples were diluted 1:100 in fresh TSB and incubated for $5 \mathrm{~h}$ at $37^{\circ} \mathrm{C}$ with shaking at $200 \mathrm{rpm}$. Samples were centrifuged at 4,200 rpm for $10 \mathrm{~min}$. The supernatants from the test strains were collected and filter sterilized through a 0.22 -nm-pore-size syringe filter and mixed 2:1 with fresh TSB. The reporter strain pellets were then resuspended in $5 \mathrm{ml}$ of the 2:1 conditioned medium-fresh medium mix and incubated for an additional $3 \mathrm{~h}$. The bacteria were washed twice in $3.5 \mathrm{ml}$ PBS and resuspended in $1 \mathrm{ml}$ of PBS. Samples were then diluted 1:1 in PBS and aliquoted in triplicate into a clear-bottom 96 -well black plate. The bacterial optical density $\left(\mathrm{OD}_{600}\right)$ and GFP fluorescence (excitation wavelength, $495 \mathrm{~nm}$; emission wavelength, $509 \mathrm{~nm}$ ) were measured using a BioTek Synergy H1 microplate reader. The data were normalized and displayed as GFP fluorescence/OD.

Generation of murine BMM. Murine bone marrow-derived macrophages (BMM) were differentiated from the bone marrow of 6- to 8-week-old female or male C57BL/6J (WT), TLR2 ${ }^{-1-}$, TLR4 ${ }^{-1-}$, and MyD88 ${ }^{-1-}$ mice as previously described (47).

Macrophage cytokine profiles. Bacteria were grown overnight in triplicate in a 96-well roundbottom plate (Corning) in $150 \mu \mathrm{l}$ of TSB at $37^{\circ} \mathrm{C}$ with shaking at $200 \mathrm{rpm}$. Samples were diluted 1:50 in $147 \mu \mathrm{l}$ of fresh TSB in a 96-well round-bottom plate and incubated for $8 \mathrm{~h}$ at $37^{\circ} \mathrm{C}$ with shaking at $200 \mathrm{rpm}$. Bacterial growth was assessed by reading the $\mathrm{OD}_{600}$, followed by centrifugation at 3,700 rpm for $15 \mathrm{~min}$ to pellet the cells. The supernatants were collected and stored at $-80^{\circ} \mathrm{C}$. Primary bone marrow-derived macrophages (BMM) from WT, $\mathrm{TLR2}^{-1-}, \mathrm{TLR}^{-1-}$, and $\mathrm{MyD}^{-1} 8^{-1-}$ mice were thawed and incubated at $37^{\circ} \mathrm{C}$ with $5 \% \mathrm{CO}_{2}$ for $48 \mathrm{~h}$ before seeding in a 96-well plate at 65,000 cells per well. The BMM were allowed to rest overnight before being treated with $10 \mu \mathrm{l}$ of thawed bacterial supernatant for $24 \mathrm{~h}$ at $37^{\circ} \mathrm{C}$ with $5 \% \mathrm{CO}_{2}$. After $24 \mathrm{~h}, 50 \mu \mathrm{l}$ of the supernatants was collected and stored at $-80^{\circ} \mathrm{C}$. To assess cytokine levels, a BD cytometric bead array mouse soluble protein set and a soluble protein master buffer kit were used. The assay was conducted using the manufacturer's instructions.

Rabbit RBC lysis assay. For relative quantitation of the hemolytic activity of WT S. aureus and the mutants, strains were grown overnight in a round-bottom 96-well plate in TSB with shaking at $37^{\circ} \mathrm{C}$. On the next day, overnight cultures were diluted (1:50) in $150 \mu$ l TSB in a 96-well round-bottom plate and incubated at $37^{\circ} \mathrm{C}$ with shaking for $6 \mathrm{~h}$. A $2 \%$ suspension of defibrinated rabbit red blood cells (RBCs; Hemostat) was prepared by washing the cells twice in $1 \times$ phosphate-buffered saline (PBS) and diluting cells from the stock RBC packed cell volume in PBS to a final concentration of $2 \% \mathrm{RBC}$. This preparation was kept on ice until use. After $6 \mathrm{~h}$, the bacterial culture was centrifuged for $5 \mathrm{~min}$ at 3,900 rpm. One hundred microliters of $\mathrm{OD}_{600}$-normalized cell-free supernatants was added to the top row of roundbottom 96-well plates, and a 2-fold serial dilution series was set up with these supernatants. To each supernatant dilution, $2 \% \mathrm{RBCs}$ were added $(1: 1)$, followed by incubation for $1 \mathrm{~h}$ at $37^{\circ} \mathrm{C}$. The plates were then centrifuged for $5 \mathrm{~min}$ at 1,500 rpm to pellet the nonlysed RBCs, the supernatants were transferred to a flat-bottom 96-well plate, and red blood cell lysis was measured at $\mathrm{OD}_{450}$ on a spectrophotometer.

Murine skin and soft tissue infection model. Cultures of the wild-type, $\triangle m r o Q, \triangle m r o Q+m r o Q$, $\Delta m r o Q+m r o Q(E 141 A), \Delta m r o Q+m r o Q(E 142 A), \triangle m r o Q+m r o Q(H 180 A)$, and $\triangle a g r$ strains were inoculated from freshly isolated single colonies and grown with shaking at $200 \mathrm{rpm}$ at $37^{\circ} \mathrm{C}$ overnight. On the next day, a 1:100 subculture in $15 \mathrm{ml}$ of TSB was incubated at $37^{\circ} \mathrm{C}$ for $3 \mathrm{~h}$ with shaking. Cultures were then centrifuged for $5 \mathrm{~min}$ at maximum speed, and cell pellets were washed twice in $5 \mathrm{ml} \mathrm{PBS}$. Bacterial suspensions were diluted $2 \mathrm{ml}$ into $8 \mathrm{ml}$ of PBS, normalized with $\mathrm{PBS}$ to an $\mathrm{OD}_{600}$ of approximately 0.32 to $0.33\left(1 \times 10^{8} \mathrm{CFU} / \mathrm{ml}\right)$, and mixed 1:1 with sterile Cytodex beads (Sigma). The mice were deeply anesthetized with 2,2,2-tribromoethanol (Avertin; Sigma) via intraperitoneal injection, followed by removal of fur and infection with $100 \mu$ I PBS containing $1 \times 10^{7}$ CFU of bacteria and Cytodex beads on the right and left sides by intradermal injection. Mice were monitored daily; and at 72 or $120 \mathrm{~h}$ postinfection, they were euthanized. Skin abscesses were collected, homogenized, spread onto TSA plates, and incubated overnight at $37^{\circ} \mathrm{C}$ in order to enumerate the CFU. Skin homogenates were also used for cytometric bead array analysis of local cytokine levels as described above.

Ethics statement. All experiments were performed following the ethical standards of the institutional Biosafety Committee and the Institutional Animal Care and Use Committee (IACUC) at Loyola University Chicago, Health Sciences Division. The institution is approved by the Public Health Service (PHS; A3117-01 through 28 February 2022), is fully accredited by AAALAC International (000180, certification dated 17 November 2016), and is registered/licensed by USDA (33-R-0024 through 24 August 2020). All animal experiments were performed in animal biosafety level 2 facilities with IACUCapproved protocols (IACUC protocol 2017028) under the guidance of the Office of Laboratory Animal Welfare (OLAW) following USDA and PHS policy and guidelines on the humane care and use of laboratory animals.

Statistical analyses. All experiments were repeated at least three independent times. For in vitro macrophage and AIP reporter data, statistical significance was analyzed with data from representative experiments that were conducted in triplicate and that were repeated a minimum of three independent times. All statistical significance was analyzed using GraphPad Prism (version 7.0) software by the statistical tests specified in the figure legends. Prior to conducting statistical analyses on data derived 
from animal studies, a D'Agostino and Pearson or Shapiro-Wilk normality test was conducted. Based on normality testing, either analysis of variance (ANOVA) or a nonparametric test was performed. Post hoc statistical significance was calculated using Dunn's post hoc test. The number of animals per treatment group is indicated by the $n$ values in the figure legends. For all other data, statistical significance $(P<0.05)$ was determined by one-way ANOVA with Tukey's post hoc test.

\section{SUPPLEMENTAL MATERIAL}

Supplemental material for this article may be found at https://doi.org/10.1128/IAI .00019-19.

SUPPLEMENTAL FILE 1, PDF file, 9 MB.

\section{ACKNOWLEDGMENTS}

We thank the members of the F. Alonzo laboratory for helpful discussions and Alex

Argianas for assistance with preliminary studies that helped guide project directions.

This work was supported by grants NIH R01 Al120994 (to F.A.), AHA 17 PRE33660173

(to J.P.G.), and AHA 19POST34380259 (to W.P.T.).

\section{REFERENCES}

1. Monnet V, Juillard V, Gardan R. 2016. Peptide conversations in Grampositive bacteria. Crit Rev Microbiol 42:339-351. https://doi.org/10 .3109/1040841X.2014.948804.

2. Cook LC, Federle MJ. 2014. Peptide pheromone signaling in Streptococcus, and Enterococcus. FEMS Microbiol Rev 38:473-492. https://doi.org/ 10.1111/1574-6976.12046.

3. Thoendel M, Kavanaugh JS, Flack CE, Horswill AR. 2011. Peptide signaling in the staphylococci. Chem Rev 111:117-151. https://doi.org/10 1021/cr100370n.

4. Ng WL, Bassler BL. 2009. Bacterial quorum-sensing network architectures. Annu Rev Genet 43:197-222. https://doi.org/10.1146/annurev-genet102108-134304.

5. Wang B, Muir TW. 2016. Regulation of virulence in Staphylococcus aureus: molecular mechanisms and remaining puzzles. Cell Chem Biol 23: 214-224. https://doi.org/10.1016/j.chembiol.2016.01.004.

6. Lyon GJ, Novick RP. 2004. Peptide signaling in Staphylococcus aureus and other Gram-positive bacteria. Peptides 25:1389-1403. https://doi.org/10 .1016/j.peptides.2003.11.026.

7. LaSarre B, Federle MJ. 2013. Exploiting quorum sensing to confuse bacterial pathogens. Microbiol Mol Biol Rev 77:73-111. https://doi.org/ 10.1128/MMBR.00046-12.

8. O'Loughlin CT, Miller LC, Siryaporn A, Drescher K, Semmelhack MF, Bassler BL. 2013. A quorum-sensing inhibitor blocks Pseudomonas aeruginosa virulence and biofilm formation. Proc Natl Acad Sci U S A 110:17981-17986. https://doi.org/10.1073/pnas.1316981110.

9. Scutera S, Zucca M, Savoia D. 2014. Novel approaches for the design and discovery of quorum-sensing inhibitors. Expert Opin Drug Discov 9:353-366. https://doi.org/10.1517/17460441.2014.894974.

10. Remy B, Mion S, Plener L, Elias M, Chabriere E, Daude D. 2018. Interference in bacterial quorum sensing: a biopharmaceutical perspective. Front Pharmacol 9:203. https://doi.org/10.3389/fphar.2018.00203.

11. Salam AM, Quave CL. 2018. Targeting virulence in Staphylococcus aureus by chemical inhibition of the accessory gene regulator system in vivo. mSphere 3:e00500-17. https://doi.org/10.1128/mSphere.00500-17.

12. Brackman G, Coenye T. 2015. Inhibition of quorum sensing in Staphylococcus spp. Curr Pharm Des 21:2101-2108. https://doi.org/10.2174/ 1381612821666150310101014

13. Parashar V, Aggarwal C, Federle MJ, Neiditch MB. 2015. Rgg protein structure-function and inhibition by cyclic peptide compounds. Proc Natl Acad Sci U S A 112:5177-5182. https://doi.org/10.1073/pnas 1500357112

14. Quave CL, Horswill AR. 2018. Identification of staphylococcal quorum sensing inhibitors by quantification of õ-hemolysin with high performance liquid chromatography. Methods Mol Biol 1673:363-370. https:// doi.org/10.1007/978-1-4939-7309-5 27.

15. Le KY, Otto M. 2015. Quorum-sensing regulation in staphylococci-an overview. Front Microbiol 6:1174. https://doi.org/10.3389/fmicb.2015 .01174.

16. Liu Q, Yeo WS, Bae T. 2016. The SaeRS two-component system of Staphylococcus aureus. Genes (Basel) 7:E81.

17. Cheung AL, Zhang G. 2002. Global regulation of virulence determinants in Staphylococcus aureus by the SarA protein family. Front Biosci 7:d1825-d1842. https://doi.org/10.2741/A882.

18. Burgui S, Gil C, Solano C, Lasa I, Valle J. 2018. A systematic evaluation of the two-component systems network reveals that ArIRS is a key regulator of catheter colonization by Staphylococcus aureus. Front Microbiol 9:342. https://doi.org/10.3389/fmicb.2018.00342.

19. Walker JN, Crosby HA, Spaulding AR, Salgado-Pabon W, Malone CL, Rosenthal CB, Schlievert PM, Boyd JM, Horswill AR. 2013. The Staphylococcus aureus ArIRS two-component system is a novel regulator of agglutination and pathogenesis. PLoS Pathog 9:e1003819. https://doi .org/10.1371/journal.ppat.1003819.

20. Kinkel TL, Roux CM, Dunman PM, Fang FC. 2013. The Staphylococcus aureus SrrAB two-component system promotes resistance to nitrosative stress and hypoxia. mBio 4:e00696-13. https://doi.org/10.1128/ mBio.00696-13.

21. Hall JW, Yang J, Guo H, Ji Y. 2015. The AirSR two-component system contributes to Staphylococcus aureus survival in human blood and transcriptionally regulates sspABC operon. Front Microbiol 6:682. https://doi .org/10.3389/fmicb.2015.00682.

22. Xue T, You Y, Hong D, Sun H, Sun B. 2011. The Staphylococcus aureus KdpDE two-component system couples extracellular $\mathrm{K}^{+}$sensing and Agr signaling to infection programming. Infect Immun 79:2154-2167. https://doi.org/10.1128/IAI.01180-10.

23. Watkins RL, Zurek OW, Pallister KB, Voyich JM. 2013. The SaeR/S twocomponent system induces interferon-gamma production in neutrophils during invasive Staphylococcus aureus infection. Microbes Infect 15:749-754. https://doi.org/10.1016/j.micinf.2013.05.004.

24. Yang SJ, Bayer AS, Mishra NN, Meehl M, Ledala N, Yeaman MR, Xiong YQ, Cheung AL. 2012. The Staphylococcus aureus two-component regulatory system, GraRS, senses and confers resistance to selected cationic antimicrobial peptides. Infect Immun 80:74-81. https://doi.org/10.1128/IAI .05669-11.

25. Yang SJ, Xiong YQ, Yeaman MR, Bayles KW, Abdelhady W, Bayer AS. 2013. Role of the LytSR two-component regulatory system in adaptation to cationic antimicrobial peptides in Staphylococcus aureus. Antimicrob Agents Chemother 57:3875-3882. https://doi.org/10.1128/AAC.00412-13.

26. Novick RP, Projan SJ, Kornblum J, Ross HF, Ji G, Kreiswirth B, Vandenesch F, Moghazeh S. 1995. The agr P2 operon: an autocatalytic sensory transduction system in Staphylococcus aureus. Mol Gen Genet 248: 446-458. https://doi.org/10.1007/BF02191645.

27. Thoendel M, Horswill AR. 2009. Identification of Staphylococcus aureus AgrD residues required for autoinducing peptide biosynthesis. J Biol Chem 284:21828-21838. https://doi.org/10.1074/jbc.M109.031757.

28. Zhang L, Gray L, Novick RP, Ji G. 2002. Transmembrane topology of AgrB, the protein involved in the post-translational modification of AgrD in Staphylococcus aureus. J Biol Chem 277:34736-34742. https://doi.org/10 .1074/jbc.M205367200.

29. Wang B, Zhao A, Novick RP, Muir TW. 2015. Key driving forces in the biosynthesis of autoinducing peptides required for staphylococcal virulence. Proc Natl Acad Sci U S A 112:10679-10684. https://doi.org/10 $.1073 /$ pnas. 1506030112 . 
30. Zhang L, Ji G. 2004. Identification of a staphylococcal AgrB segment(s) responsible for group-specific processing of AgrD by gene swapping J Bacteriol 186:6706-6713. https://doi.org/10.1128/JB.186.20.6706 $-6713.2004$.

31. Zhang L, Lin J, Ji G. 2004. Membrane anchoring of the AgrD N-terminal amphipathic region is required for its processing to produce a quorumsensing pheromone in Staphylococcus aureus. J Biol Chem 279: 19448-19456. https://doi.org/10.1074/jbc.M311349200.

32. Kavanaugh JS, Thoendel M, Horswill AR. 2007. A role for type I signal peptidase in Staphylococcus aureus quorum sensing. Mol Microbiol 65: 780-798. https://doi.org/10.1111/j.1365-2958.2007.05830.x.

33. Geisinger E, Chen J, Novick RP. 2012. Allele-dependent differences in quorum-sensing dynamics result in variant expression of virulence genes in Staphylococcus aureus. J Bacteriol 194:2854-2864. https://doi .org/10.1128/JB.06685-11.

34. Wang B, Zhao A, Xie Q, Olinares PD, Chait BT, Novick RP, Muir TW. 2017. Functional plasticity of the AgrC receptor histidine kinase required for staphylococcal virulence. Cell Chem Biol 24:76-86. https://doi.org/10 .1016/j.chembiol.2016.12.008.

35. Tal-Gan Y, Ivancic M, Cornilescu G, Blackwell HE. 2016. Characterization of structural elements in native autoinducing peptides and non-native analogues that permit the differential modulation of AgrC-type quorum sensing receptors in Staphylococcus aureus. Org Biomol Chem 14: 113-121. https://doi.org/10.1039/c5ob01735a.

36. Wang B, Zhao A, Novick RP, Muir TW. 2014. Activation and inhibition of the receptor histidine kinase AgrC occurs through opposite helical transduction motions. Mol Cell 53:929-940. https://doi.org/10.1016/j molcel.2014.02.029.

37. Geisinger E, Muir TW, Novick RP. 2009. agr receptor mutants reveal distinct modes of inhibition by staphylococcal autoinducing peptides. Proc Natl Acad Sci U S A 106:1216-1221. https://doi.org/10.1073/pnas .0807760106 .

38. Geisinger E, George EA, Chen J, Muir TW, Novick RP. 2008. Identification of ligand specificity determinants in AgrC, the Staphylococcus aureus quorum-sensing receptor. J Biol Chem 283:8930-8938. https://doi.org/ 10.1074/jbc.M710227200.

39. Lyon GJ, Wright JS, Muir TW, Novick RP. 2002. Key determinants of receptor activation in the agr autoinducing peptides of Staphylococcus aureus. Biochemistry 41:10095-10104. https://doi.org/10.1021/bi026049u.

40. Ji G, Beavis R, Novick RP. 1997. Bacterial interference caused by autoinducing peptide variants. Science 276:2027-2030. https://doi.org/10 .1126/science.276.5321.2027.

41. Wright JS, III, Traber KE, Corrigan R, Benson SA, Musser JM, Novick RP. 2005. The agr radiation: an early event in the evolution of staphylococci. J Bacteriol 187:5585-5594. https://doi.org/10.1128/JB.187.16.5585-5594 .2005 .

42. Jarraud S, Mougel C, Thioulouse J, Lina G, Meugnier H, Forey F, Nesme X, Etienne J, Vandenesch F. 2002. Relationships between Staphylococcus aureus genetic background, virulence factors, agr groups (alleles), and human disease. Infect Immun 70:631-641. https://doi.org/10.1128/IAI.70 .2.631-641.2002.

43. Cheung $A L$, Eberhardt KJ, Chung E, Yeaman MR, Sullam PM, Ramos $M$, Bayer AS. 1994. Diminished virulence of a sar-/agr- mutant of Staphylococcus aureus in the rabbit model of endocarditis. J Clin Invest 94: 1815-1822. https://doi.org/10.1172/JCl117530.

44. Heyer G, Saba S, Adamo R, Rush W, Soong G, Cheung A, Prince A. 2002. Staphylococcus aureus agr and sarA functions are required for invasive infection but not inflammatory responses in the lung. Infect Immun 70:127-133. https://doi.org/10.1128/IAI.70.1.127-133.2002.

45. Kobayashi SD, Malachowa N, Whitney AR, Braughton KR, Gardner DJ, Long D, Bubeck Wardenburg J, Schneewind O, Otto M, Deleo FR. 2011. Comparative analysis of USA300 virulence determinants in a rabbit model of skin and soft tissue infection. J Infect Dis 204:937-941. https:// doi.org/10.1093/infdis/jir441.

46. Montgomery CP, Boyle-Vavra S, Daum RS. 2010. Importance of the global regulators Agr and SaeRS in the pathogenesis of CA-MRSA USA300 infection. PLoS One 5:e15177. https://doi.org/10.1371/journal .pone.0015177.

47. Grayczyk JP, Harvey CJ, Laczkovich I, Alonzo F, III. 2017. A lipoylated metabolic protein released by Staphylococcus aureus suppresses macrophage activation. Cell Host Microbe 22:678-687.e9. https://doi.org/10 .1016/j.chom.2017.09.004.

48. Laczkovich I, Teoh WP, Flury S, Grayczyk JP, Zorzoli A, Alonzo F, III. 16 April
2018. Increased flexibility in the use of exogenous lipoic acid by Staphylococcus aureus. Mol Microbiol https://doi.org/10.1111/mmi.13970.

49. Zorzoli A, Grayczyk JP, Alonzo F, III. 2016. Staphylococcus aureus tissue infection during sepsis is supported by differential use of bacterial or host-derived lipoic acid. PLoS Pathog 12:e1005933. https://doi.org/10 .1371/journal.ppat.1005933.

50. Pei J, Mitchell DA, Dixon JE, Grishin NV. 2011. Expansion of type II CAAX proteases reveals evolutionary origin of gamma-secretase subunit APH-1. J Mol Biol 410:18-26. https://doi.org/10.1016/j.jmb.2011.04.066.

51. Kjos M, Borrero J, Opsata M, Birri DJ, Holo H, Cintas LM, Snipen L, Hernandez PE, Nes IF, Diep DB. 2011. Target recognition, resistance, immunity and genome mining of class II bacteriocins from Grampositive bacteria. Microbiology 157:3256-3267. https://doi.org/10.1099/ mic.0.052571-0.

52. Ellermeier CD, Losick R. 2006. Evidence for a novel protease governing regulated intramembrane proteolysis and resistance to antimicrobial peptides in Bacillus subtilis. Genes Dev 20:1911-1922. https://doi.org/10 $.1101 /$ gad.1440606.

53. Biswas S, Biswas I. 2014. A conserved streptococcal membrane protein, LsrS, exhibits a receptor-like function for lantibiotics. J Bacteriol 196: 1578-1587. https://doi.org/10.1128/JB.00028-14.

54. Draper LA, Cotter PD, Hill C, Ross RP. 2015. Lantibiotic resistance. Microbiol Mol Biol Rev 79:171-191. https://doi.org/10.1128/MMBR.00051-14.

55. O'Connor L, Coffey A, Daly C, Fitzgerald GF. 1996. AbiG, a genotypically novel abortive infection mechanism encoded by plasmid pCl750 of Lactococcus lactis subsp. cremoris UC653. Appl Environ Microbiol 62: 3075-3082.

56. Frankel MB, Wojcik BM, DeDent AC, Missiakas DM, Schneewind O. 2010. $A B I$ domain-containing proteins contribute to surface protein display and cell division in Staphylococcus aureus. Mol Microbiol 78:238-252. https://doi.org/10.1111/j.1365-2958.2010.07334.x.

57. Grundling A, Missiakas DM, Schneewind O. 2006. Staphylococcus aureus mutants with increased lysostaphin resistance. J Bacteriol 188:6286-6297. https://doi.org/10.1128/JB.00457-06.

58. Poupel O, Proux C, Jagla B, Msadek T, Dubrac S. 2018. SpdC, a novel virulence factor, controls histidine kinase activity in Staphylococcus aureus. PLoS Pathog 14:e1006917. https://doi.org/10.1371/journal.ppat .1006917 .

59. Firon A, Tazi A, Da Cunha V, Brinster S, Sauvage E, Dramsi S, Golenbock DT, Glaser P, Poyart C, Trieu-Cuot P. 2013. The Abi-domain protein Abx1 interacts with the CovS histidine kinase to control virulence gene expression in group B Streptococcus. PLoS Pathog 9:e1003179. https://doi .org/10.1371/journal.ppat.1003179.

60. Foster TJ, Geoghegan JA, Ganesh VK, Hook M. 2014. Adhesion, invasion and evasion: the many functions of the surface proteins of Staphylococcus aureus. Nat Rev Microbiol 12:49-62. https://doi.org/ 10.1038/nrmicro3161.

61. Qoronfleh MW, Streips UN, Wilkinson BJ. 1990. Basic features of the staphylococcal heat shock response. Antonie Van Leeuwenhoek 58: 79-86. https://doi.org/10.1007/BF00422721.

62. Chen J, Yoong P, Ram G, Torres VJ, Novick RP. 2014. Single-copy vectors for integration at the SaPI1 attachment site for Staphylococcus aureus. Plasmid 76:1-7. https://doi.org/10.1016/j.plasmid.2014.08.001.

63. Alonzo F, III, Benson MA, Chen J, Novick RP, Shopsin B, Torres VJ. 2012. Staphylococcus aureus leucocidin ED contributes to systemic infection by targeting neutrophils and promoting bacterial growth in vivo. Mol Microbiol 83:423-435. https://doi.org/10.1111/j.1365-2958 .2011.07942.x.

64. Fey PD, Endres JL, Yajjala VK, Widhelm TJ, Boissy RJ, Bose JL, Bayles KW. 2013. A genetic resource for rapid and comprehensive phenotype screening of nonessential Staphylococcus aureus genes. mBio 4:e00537-12. https:// doi.org/10.1128/mBio.00537-12.

65. Painter KL, Krishna A, Wigneshweraraj S, Edwards AM. 2014. What role does the quorum-sensing accessory gene regulator system play during Staphylococcus aureus bacteremia? Trends Microbiol 22: 676-685. https://doi.org/10.1016/j.tim.2014.09.002.

66. Yarwood JM, Bartels DJ, Volper EM, Greenberg EP. 2004. Quorum sensing in Staphylococcus aureus biofilms. J Bacteriol 186:1838-1850. https:// doi.org/10.1128/JB.186.6.1838-1850.2004.

67. Dumont $A L$, Yoong $P$, Day $C J$, Alonzo F, III, McDonald $W H$, Jennings MP, Torres VJ. 2013. Staphylococcus aureus LukAB cytotoxin kills human neutrophils by targeting the CD11b subunit of the integrin Mac-1. Proc Natl Acad Sci U S A 110:10794-10799. https://doi.org/10.1073/pnas .1305121110 
68. DuMont AL, Yoong $P$, Surewaard BG, Benson MA, Nijland R, van Strijp JA, Torres VJ. 2013. Staphylococcus aureus elaborates leukocidin AB to mediate escape from within human neutrophils. Infect Immun 81: 1830-1841. https://doi.org/10.1128/IAI.00095-13.

69. Kjos M, Snipen L, Salehian Z, Nes IF, Diep DB. 2010. The Abi proteins and their involvement in bacteriocin self-immunity. J Bacteriol 192: 2068-2076. https://doi.org/10.1128/JB.01553-09.

70. Heinrich J, Wiegert T. 2006. YpdC determines site-1 degradation in regulated intramembrane proteolysis of the RsiW anti-sigma factor of Bacillus subtilis. Mol Microbiol 62:566-579. https://doi.org/10.1111/j .1365-2958.2006.05391.x.

71. Dolence JM, Steward LE, Dolence EK, Wong DH, Poulter CD. 2000. Studies with recombinant Saccharomyces cerevisiae CaaX prenyl protease Rce1p. Biochemistry 39:4096-4104. https://doi.org/10.1021/bi9923611.

72. Plummer LJ, Hildebrandt ER, Porter SB, Rogers VA, McCracken J, Schmidt WK. 2006. Mutational analysis of the Ras converting enzyme reveals a requirement for glutamate and histidine residues. J Biol Chem 281: 4596-4605. https://doi.org/10.1074/jbc.M506284200.

73. Autret N, Raynaud C, Dubail I, Berche P, Charbit A. 2003. Identification of the agr locus of Listeria monocytogenes: role in bacterial virulence. Infect Immun 71:4463-4471. https://doi.org/10.1128/IAI.71.8.4463-4471.2003.

74. Riedel CU, Monk IR, Casey PG, Waidmann MS, Gahan CG, Hill C. 2009. AgrD-dependent quorum sensing affects biofilm formation, invasion, virulence and global gene expression profiles in Listeria monocytogenes. Mol Microbiol 71:1177-1189. https://doi.org/10.1111/j.1365-2958.2008 .06589.x.

75. Zetzmann M, Sanchez-Kopper A, Waidmann MS, Blombach B, Riedel CU. 2016. Identification of the Agr peptide of Listeria monocytogenes. Front Microbiol 7:989. https://doi.org/10.3389/fmicb.2016.00989.

76. Paspaliari DK, Mollerup MS, Kallipolitis $\mathrm{BH}$, Ingmer $\mathrm{H}$, Larsen $\mathrm{MH}$. 2014. Chitinase expression in Listeria monocytogenes is positively regulated by the Agr system. PLoS One 9:e95385. https://doi.org/10 .1371/journal.pone.0095385.

77. Martin MJ, Clare S, Goulding D, Faulds-Pain A, Barquist L, Browne HP, Pettit L, Dougan G, Lawley TD, Wren BW. 2013. The agr locus regulates virulence and colonization genes in Clostridium difficile 027. J Bacteriol 195:3672-3681. https://doi.org/10.1128/JB.00473-13.

78. Qin X, Singh KV, Weinstock GM, Murray BE. 2000. Effects of Enterococcus faecalis fsr genes on production of gelatinase and a serine protease and virulence. Infect Immun 68:2579-2586. https://doi.org/10.1128/IAI.68.5 .2579-2586.2000.

79. Engelbert M, Mylonakis E, Ausubel FM, Calderwood SB, Gilmore MS. 2004. Contribution of gelatinase, serine protease, and fsr to the pathogenesis of Enterococcus faecalis endophthalmitis. Infect Immun 72: 3628-3633. https://doi.org/10.1128/IAI.72.6.3628-3633.2004.

80. Cho JS, Zussman J, Donegan NP, Ramos RI, Garcia NC, Uslan DZ, Iwakura Y, Simon SI, Cheung AL, Modlin RL, Kim J, Miller LS. 2011. Noninvasive in vivo imaging to evaluate immune responses and antimicrobial therapy against Staphylococcus aureus and USA300 MRSA skin infections. J Invest Dermatol 131:907-915. https://doi.org/10.1038/jid.2010.417.

81. Melehani JH, Duncan JA. 2016. Inflammasome activation can mediate tissue-specific pathogenesis or protection in Staphylococcus aureus infection. Curr Top Microbiol Immunol 397:257-282. https://doi.org/10 .1007/978-3-319-41171-2_13.

82. Miller LS, Cho JS. 2011. Immunity against Staphylococcus aureus cutaneous infections. Nat Rev Immunol 11:505-518. https://doi.org/10.1038/ nri3010.

83. Miller LS, O'Connell RM, Gutierrez MA, Pietras EM, Shahangian A, Gross
CE, Thirumala A, Cheung AL, Cheng G, Modlin RL. 2006. MyD88 mediates neutrophil recruitment initiated by IL-1R but not TLR2 activation in immunity against Staphylococcus aureus. Immunity 24:79-91. https://doi .org/10.1016/j.immuni.2005.11.011.

84. Miller LS, Pietras EM, Uricchio LH, Hirano K, Rao S, Lin H, O'Connell RM, Iwakura Y, Cheung AL, Cheng G, Modlin RL. 2007. Inflammasome-mediated production of IL-1beta is required for neutrophil recruitment against Staphylococcus aureus in vivo. J Immunol 179:6933-6942. https://doi.org/10 .4049/jimmunol.179.10.6933.

85. Kitur K, Wachtel S, Brown A, Wickersham M, Paulino F, Penaloza HF, Soong G, Bueno S, Parker D, Prince A. 2016. Necroptosis promotes Staphylococcus aureus clearance by inhibiting excessive inflammatory signaling. Cell Rep 16:2219-2230. https://doi.org/10.1016/j.celrep.2016 .07.039.

86. Powers ME, Becker RE, Sailer A, Turner JR, Bubeck Wardenburg J. 2015. Synergistic action of Staphylococcus aureus alpha-toxin on platelets and myeloid lineage cells contributes to lethal sepsis. Cell Host Microbe 17:775-787. https://doi.org/10.1016/j.chom.2015.05.011.

87. Benson MA, Lilo S, Wasserman GA, Thoendel M, Smith A, Horswill AR, Fraser J, Novick RP, Shopsin B, Torres VJ. 2011. Staphylococcus aureus regulates the expression and production of the staphylococcal superantigen-like secreted proteins in a Rot-dependent manner. Mol Microbiol 81:659-675. https:// doi.org/10.1111/j.1365-2958.2011.07720.x.

88. Bebbington C, Yarranton G. 2008. Antibodies for the treatment of bacterial infections: current experience and future prospects. Curr Opin Biotechnol 19:613-619. https://doi.org/10.1016/j.copbio.2008.10.002.

89. Tan L, Li SR, Jiang B, Hu XM, Li S. 2018. Therapeutic targeting of the Staphylococcus aureus accessory gene regulator (agr) system. Front Microbiol 9:55. https://doi.org/10.3389/fmicb.2018.00055.

90. Dickey SW, Cheung GYC, Otto M. 2017. Different drugs for bad bugs: antivirulence strategies in the age of antibiotic resistance. Nat Rev Drug Discov 16:457-471. https://doi.org/10.1038/nrd.2017.23.

91. Boles BR, Thoendel M, Roth AJ, Horswill AR. 2010. Identification of genes involved in polysaccharide-independent Staphylococcus aureus biofilm formation. PLoS One 5:e10146. https://doi.org/10.1371/ journal.pone.0010146.

92. Howell-Adams B, Seifert HS. 2000. Molecular models accounting for the gene conversion reactions mediating gonococcal pilin antigenic variation. Mol Microbiol 37:1146-1158. https://doi.org/10.1046/j.1365-2958 .2000.02067.x.

93. Monk IR, Shah IM, Xu M, Tan MW, Foster TJ. 2012. Transforming the untransformable: application of direct transformation to manipulate genetically Staphylococcus aureus and Staphylococcus epidermidis. mBio 3:e00277-11. https://doi.org/10.1128/mBio.00277-11.

94. Riedel CU, Monk IR, Casey PG, Morrissey D, O'Sullivan GC, Tangney M, Hill C, Gahan CG. 2007. Improved luciferase tagging system for Listeria monocytogenes allows real-time monitoring in vivo and in vitro. Appl Environ Microbiol 73:3091-3094. https://doi.org/10.1128/AEM.02940-06.

95. Forsgren A, Sjoquist J. 1966. Protein A from S. aureus. I. Pseudo-immune reaction with human gamma-globulin. J Immunol 97:822-827.

96. Fairweather N, Kennedy S, Foster TJ, Kehoe M, Dougan G. 1983. Expression of a cloned Staphylococcus aureus alpha-hemolysin determinant in Bacillus subtilis and Staphylococcus aureus. Infect Immun 41:1112-1117.

97. Benson MA, Lilo S, Nygaard T, Voyich JM, Torres VJ. 2012. Rot and SaeRS cooperate to activate expression of the staphylococcal superantigen-like exoproteins. J Bacteriol 194:4355-4365. https://doi.org/10.1128/JB .00706-12. 